PNL --7277

DE9 I 000052

\title{
PERFORMANCE TESTING OF EXTREMITY DOSIMETERS AGAINST A DRAFT STANDARD
}
R. Harty
W. D. Reece
C. D. Hocker
J. C. MeDonald
J. M. Selby, PNL Program Manager
R. M. Loesch, DOE Program Manager

September 1990

Prepared for the U.S. Department of Energy under Contract DE-ACO6-76RLO 1830

Pacific Northwest Laboratory

Richland, Washington 99352 


\section{FOREWORD}

The assurance of worker radiation safety is directly related to the performance of personnel dosimetry. The U.S. Department of Energy (DOE) has long recognized this critical relationship and has addressed this issue by instituting the DOE Laboratory Accreditation Program (DOELAP) which strives to improve the quality of personnel dosimetry through performance testing, dosimetry calibration, intercomparisons, evaluations and accreditations.

One area of personnel dosimetry that has not been specifically addressed by DOELAP is extremity dosimeter testing. The number of workers that are routinely exposed to extremity dose in excess of their whole-body dose is a relatively small fraction of the overall worker population. However, there is a potential for these doses to be quite high. Only when accurate dosimeter measurements are available can a reliable estimate of extremity dose be made.

This task was directed at assessing the problems of implementing extremity dosimeter performance testing. A series of performance tests were made based on a draft standard written by the Health Physics Society Standards Committee (HPSSC) using extremity dosimeters currently in use at DOE and DOE contractor facilities. The results of this study indicate the need to incorporate performance testing of extremity dosimetry systems into DOELAP. Based on the results of this study, recommendations are made for improvements to the draft standard.

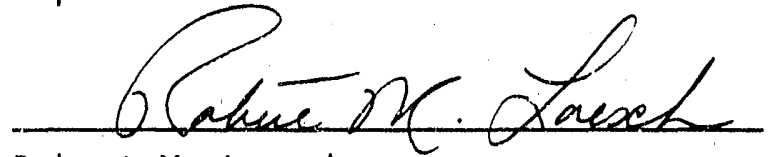

Robert M. Loesch

DOELAP Program Manager

Office of Health

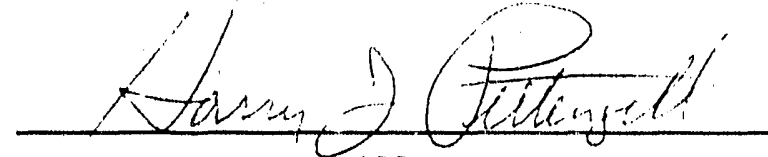

Harry J. Pettengill

Acting Deputy Assistant Secretary for Health 


\section{EXECUTIVE SUMMARY}

\section{BACKGROUND INFORMATION}

Cccupational radiation protection programs depend directly on correctly measuring the amount of radiation to which radiation workers are exposed. However, radiation measurements are subject to a variety of potential errors and uncertainties, including variations resulting from dosimeter design and manufacture (including dosimeter holder design), uncertainties due to calibration techniques, errors and variations in reading equipment and techniques, variations in the angular response of dosimeters, and uncertainties resulting from placement and use of the dosimeter. To properly protect radiation workers, the uncertainty in the quantification of radiation dose should be minimized.

Based on the importance of providing accurate personnel dosimetry processing to radiation workers, the U.S. Department of Energy (DOE) published a standard, DOE/EH-0027, that defines the performance tests used to establish uniform dose assessment of personnel dosimetry systems. From this standard, the DOE Laboratory Accreditation Program (DOELAP) was developed. The DOELAP standard applies only to personnel dosimetry systems; performance tests for extremity dosimeters were excluded from the scope of the standard. However, extremity dosimetry was planned for inclusion in future revisions of the existing standard.

The DOE, Office of Health, has contracted with the Pacific Northwest Laboratory (PNL) to determine the appropriateness of a draft standard, written by the Health Physics Society Standards Committee (HPSSC), that defines performance and quality assurance criteria for extremity dosimeter processors. The draft standard, HPSSC P/N13.32, "Standard for the Performance Testing of Extremity Dosimeters," establishes the methods for testing extremity dosimetry systems, specifies the sources, energy ranges and irradiation geometries to be used during the performance testing, and suggests the performance criteria for accuracy and precision that would be used to determine compliance. 
Four DOE contractor facilities participated fully in the feasibility study for performance testing and partial results were obtained from three additional facilities. Six types of ring dosimeters and two types of wrist dosimeters were submitted for testing. The dosimeters were sent by the facilities to PNL in three separate groups. Each dosimeter was irradiated in one of seven irradiation categories and returned to the facilities. The doses were evaluated by the facilities and then sent to PNL where the test results were evaluated against the performance criterion given in the draft standard.

\section{CONCLUSIONS}

The results of the feasibility study indicated that $58 \%$ of the time the ring dosimeters passed and 55\% of the time the wrist dosimeters passed at the tolerance level specified in the draft standard. No facility passed in every category that they entered. The best performance was exhibited in the lowenergy photon category for ring dosimeters, with the dosimeters passing over $80 \%$ of the time in this category. The worst performance was observed in the beta particle category, with the ring dosimeters passing only $33 \%$ of the time. Because data was obtained from only two types of wrist dosimeters, it was difficult to appropriately compare the results obtained between categories or between sources.

The results indicate that there is a need to incorporate performance testing of extremity dosimeters into DOELAP in order to ensure that DOE facilities appropriately measure extremity dose. However, the results also indicated that changes (as discussed below) should be made to the draft standard before it is finalized and used to accredit DOE facilities that process extremity dosimeters.

\section{RECOMMENDATIONS}

Based on the information obtained during the feasibility study, it is recommended that a standard similar to the one written by the HPSSC be developed, with the following changes: 
- The beta particle category should be subdivided to provide participating facilities with the option of receiving irradiations separately from either the $204 \mathrm{Tl}$ source or the $90 \mathrm{Sr} / 90 \mathrm{Y}$ source.

- Due to the lack of appropriate flux-to-dose-equivalent conversion factors, interim values should be chosen for use in the neutron category during feasibility and pilot study programs. The interim values would be reulaced by a calculated and experimentally tested flux-to-dose-equivalent conversion factors before the standard is finalized.

- The upper value for the test range for non-accident (protection) categories should be reduced from 20 rem to 10 rem to avoid unnecessarily long exposure times, to match the lower limit of the accident categories and to be more realistic when compared with actual dose levels received at DOE facilities.

- Consideration should be given to identifying the irradiation sources to the processor in order to provide consistency with how extremity dosimeters are used under actual field conditions. 


\section{ACKNOWLEDGMENTS}

The authors would like to express their appreciation to the following persons: K. K. Large, B. T. Hogan, M. K. Murphy and L. E. Steffens for performing the dosimeter irradiations; M. R. Tinker for assisting with the dosimeter preparation and shipment; $C$. A. Conrad for assisting with data tracking; G. W. R. Endres for providing a technical review; J. R. Weber for editing the report; and $M$. Cross for typing the report. In addition, we would like to acknowledge the help of the DOE facilities that participated in this study, and R. D. Carlson and F. M. Cummings of the Radiological and Environmental Sciences Laboratory (RESL) for their guidance and review. 


\section{GLOSSARY}

Absorbed Dose (D). The energy absorbed per unit mass in a material.: The special unit of absorbed dose is the rad. The SI (International System) unit is the gray (Gy) [joule per kilogram $(\mathrm{J} / \mathrm{kg})$ ]. $1 \mathrm{~J} / \mathrm{kg}=1 \mathrm{~Gy}=$ 100 rad.

Accident Dosimetry. Determination of high levels of absorbed dose resulting from unexpected conditions.

Accuracy - the degree of agreement of a measurement with the true value. In this report the bias is used to ascertain the accuracy of the measurements.

Bias (B). The average of the performance quotients, $\mathrm{P}_{i}$, for $\mathrm{n}$ dosimeters, for a specified irradiation category and depth

$$
B=\frac{1}{n} \sum_{i=1}^{n} P_{i}
$$

Dose Equivalent $(H)$. The product of the absorbed dose (D), the quality factor $(Q)$, and any other modifying factors. The special unit is the rem. When D is expressed in Gy, $H$ is in Sieverts (SV). 1 SV $=100$ rem.

Dosimeter. A combination of absorbers and a radiation-sensitive element or elements packaged in a holder (the holder being considered as part of the dosimeter) that is used to provide a cumulative record of absorbed dose or dose equivalent received by an individual.

Exposure-to-Dose-Equivalent Conversion Factor for Photons $\left(C_{x}\right)$. The ratio of exposure in air to the dose equivalent at a specified depth in a material of specified geometry and composition. The $C_{x}$ factors are a function of photon energy, material geometry (e.g., cylinder, sphere, slab, or torso), and material composition (e.g., a plastic tissue substitute, soft tissue ignoring trace elements, or soft tissue including trace elements).

Extremity. DOE Order 5480.11 (DOE 1988) defines extremities as "hands and arms below the elbow or feet and legs below the knee."

Extremity Dosimeter. A dosimeter designed to be worn on an extremity.

Extremity Dosimetry System. A system used to assess dose equivalent from external radiation to the extremities.

Field Calibration. The dosimeter calibration applicable to the occupational environment of intended use. 
Free-Field Dose Equivalent. The dose equivalent assigned for neutron irradiation by assuming that the irradiation is performed in free space with no background from air and room scattering and no source asymmetry

(Schwartz and Eisenhauer 1982).

Irradiation Category. Radiation type, energy and dose levels for which the accreditation tests are performed.

Performance Criterion. Used to evaluate dosimeter performance. The formula is

$$
\text { I.B } I+S \leq L
$$

where $B$ is the bias, $S$ is the standard deviation, and $L$ is the tolerance level.

Performance Quotient $\left(P_{i}\right)$. The fractional difference between the reported and delivered absorbed dose or dose equivalent for the $i$ th dosimeter,

$$
P_{i}=\frac{\left[x_{i} \text { (reported) }-x_{i}(\text { delivered })\right]}{x_{i} \text { (delivered) }}
$$

where $X$ is the shallow dose equivalent $\left(H_{S}\right)$ or shallow absorbed dose $\left(D_{S}\right)$,

Precision. The degree of conformity of repeated measurements to each other, whether or not they are accurate. In this report the standard deviation is used to ascertain the precision of the measurements.

Processor. A supplier of personnel dosimetry services. These services include:

- furnishing dosimeters to the user.

- evaluating the readings of the dosimeters after their return in terms of shallow dose equivalents as prescribed in the standard,

- documenting the results, and

- reporting them to the user.

Protection Dosimetry. Determination of routine levels of dose equivalent for the purpose of controlling the dose equivalent received by radiation workers.

Reference Measurement. In the context of this report, a reference measurement is a measurement made to relate the calibration of the dosimeter with the standards used for field and testing calibration. 
Ring Dosimeter. Any dosimeter worn on the fingers of the hand to measure radiation dose.

Shallow Absorbed Dose $\left(D_{S}\right)$ or Dose Equivalent $\left(H_{S}\right)$. The absorbed dose or dose equivalent to the depth of $0.007 \mathrm{~cm}$ in a material of specified geometry and composition.

Standard Deviation (S). The standard deviation of the performance quotients, $\mathrm{P}_{i}$, calculated for $n$ dosimeters for a specified irradiation category and depth,

$$
S=\sqrt{\frac{\sum_{i=1}^{n}\left(P_{i}-B\right)^{2}}{n-1}}
$$

Test. Submission of dosimeters by a processor to a testing laboratory over a period of several months, in numbers sufficient for the specified irradiations in the test categories covered by the processor's service. A test includes:

- irradiation of the dosimeters by personnel of the testing laboratory using the type(s) of radiation specified for the test category,

- evaluation by the processor of the response of the returned dosimeters in terms of shallow dose equivalent for tests of protection monitoring and of accident monitoring,

- submission of these evaluations to the testing laboratory,

- analysis of the submitted evaluations by the testing laboratory, and

- reporting of the results of this analysis (also referred to as "test results") to the processor.

Testing Laboratory. A laboratory independent of the processor and authorized by the organization administrating the accreditation program to carry out the procedures specified in the standard.

Tolerance Level (L). The level of uncertainty on the dose equivalent that is used to evaluate dosimeter performance. The value of the tolerance level is defined in the draft standard.

Wrist Dosimeter. Any dosimeter worn on the wrist or ankle to measure radiation dose. 


\section{CONTENTS}

FOREWORD ................................ $i_{i}$

EXECUTIVE SUMMARY .................... v

BACKGROUND INFORMATION .............. v

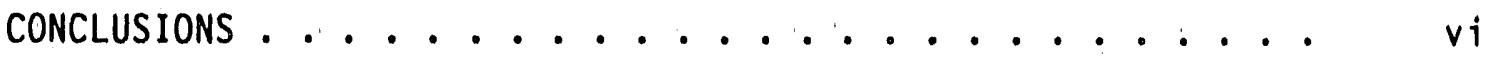

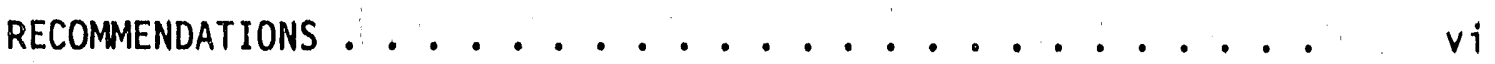

ACKNOWLEDGMENTS .......................... ix

GLOSSARY .......................................

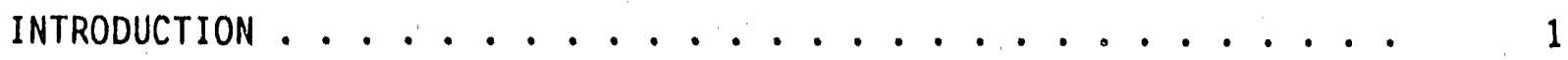

FEASIBILITY STUDY PROCEDURES ...................... 5

TEST DESIGN............................ 5

DESCRIPTION OF DOSIMETERS ................ 7

DOSIMETER HANDLING AND IRRADIATION PROCEDURES ........ 7

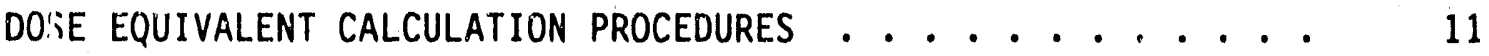

TEST EVALUATION PROCEDURES . . . . . . . . . . 15

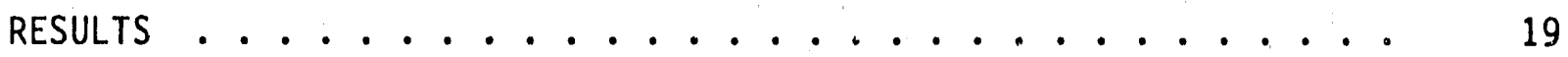

APPROPRIATENESS OF THE DRAFT STANDARD ............. 27

IRRADIATION CATEGORIES .................. 27

PERFORMANCE CRITERION .................... 28

CONCLUSIONS AND RECOMMENDATIONS ..................... 33

REFERENCES ......................... 35

APPENDIX A - ASSESSMENT OF UNCERTAINTIES . . . . . . . . A.1

APPENDIX B - COMPILATION OF DOSIMETER PERFORMANCE DATA ....... B. 1 


\section{FIGURES}

1 Bias (B) and Standard Deviation (S) for Ring Dosimeters .... 20

2 Summary of Performance ( $\mathrm{B} \mid+S)$ for Ring Dosimeters . . . 21

3 Bias (B) and Standard Deviation (S) for Wrist Dosimeters . . 22

4 Summary of Performance (I B I + S) for Wrist Dosimeters . . ... 23

5 A Comparison of the Initial and Reevaluated Doses for Ring Dosimeters.......................... 26

6 A Comparison of the Initial and Reevaluated Doses for Wrist Dosimeters ... . . . . . . . . . . . .

\section{TABLES}

1 Irradiation Categories. . . . . . . . . . . 6

2 Dosimeter Descriptions. ..................... 8

3 Exposure-to-Dose Conversion Factors for Extremity Phantoms at Shallow Dose ................。 


\section{INTRODUCTION}

Occupational radiation protection programs depend directly on correctly measuring the amount of radiation to which radiation workers are exposed. However, the measurement of radiation is subject to a variety of sources of potential error and uncertainty. Potential sources of error and uncertainty include: variations resulting from dosimeter design and manufacture (including the dosimeter holder design), uncertainties due to calibration techniques, errors and variations in reading equipment and techniques, variation in the angular response of dosimeters and uncertainties resulting from the placement of the dosimeter. The objective of a radiation protection program is to minimize the effect of errors and uncertainties in the determination of the level of radiation to which workers are exposed.

Based on the importance of providing accurate personnel dosimetry processing to radiation workers, the U.S. Department of Fnergy (DOE) has published a standard, DOE/EH-0027 that defines the performance tests used to establish a uniform dose assessment of personnel whole body dosimetry (DOE 1986). From this standard, the DOE Laboratory Accreditation Program (DOELAP) was developed by the DOE Office of Nuclear Safety (Ervironment, Safety and. Health) to improve the quality of personnel dosimetry. The stan dard describes minimum levels of acceptable performance for personnel dosimetry systems and provides procedures for testing the performance of those systems. While the DOELAP standard parallels the American National Standards Institute's (ANSI) Criteria for Testing Personnel Dosimetry Performance, ANSI N13.111 (ANSI 1983), it incorporates information and requirements specific to DOE facilities. The bases for the differences include information presented in the report Guidelines for the Calibration of Personnel Dosimeters (Roberson and Holbrook 1984), an evaluation of ANSI N13.11 conducted by the Pacific Northwest Laboratory(a) (PNL) (Roberson et al. 1983) and comments received during peer review by DOE and DOE contractor personnel.

After a draft standard for performance testing of personnel whole body dosimeters was written, a pilot performance test sponsored by the office of

(a) The Pacific Northwest Laboratory is operated for the Department of Energy by Battelie Memorial Institute under Contract DE-ACO6-76RLO 1830. 
Nuclear Safety was conducted in early 1985 by the Radiological and Environmental Sciences Laboratory, Idaho Falls (Carlson and Gesell 1986). Upon completion of the pilot performance test, DOE conducted a two year program of voluntary participation for dosimeter processors providing services to DOE facilities. DOE Order 5480.15 was issued in December, 1987, requiring DOE dosimeter processors to be accredited. The DOELAP standard applies only to personnel dosimetry systems; performance tests for extremity dosimetry were excluded from the scope of the standard. However, extremity dosimetry was planned for inclusion in future revisions of the existing standard.

As part of the continuing process to improve dosimetry practices at DOE facilities, a task was initiated in 1983 by the Department of Energy (DOE) Office of Nuclear Safety (Environment, Safety and Health) to evaluate and resolve problems associated with extremity dosimetry at DOE and DOE contractor facilities. A questionnaire and telephone survey was conducted and a report of the findings was published in 1986 (Harty, Reece and MacLellan 1986). The report showed that a wide variety of methods and algorithms were used to assess extremity dose, with little internal consistency. The results also indicated a wide range in the accuracy and precision of the dosimeters, with approximately $25 \%$ of the facilities not knowing the accuracy or precision of their extremity dosimeters.

The DOE also supported the development of standard phantoms for the calibration of extremity dosimeters and the determination of exposure-todose conversion factors $\left(C_{X}\right)$ for photons (Roberson, Eichner, and Reece 1986).

Although uniform standards governing the performance of extremity dosimetry systems do not yet exist, performance criteria for testing processors of extremity dosimeters are available in draft form. In March, 1982, the Health Physics Society Standards Committee (HPSSC) formed a working group to prepare a consensus standard defining performance and quality assurance criteria for extremity dosimeter processors. That working group has prepared a draft standard, HPSSC P/N13.32, "Standard for the Performance Testing of Extremity Dosimeters." The draft standard closely follows the ANSI and DOELAP standards for whole-body personnel dosimetry in both content and application. The draft standard: 1) establishes the methods for testing extremity dosimetry systems, 2) suggests the performance criteria for accuracy and precision 
that would be used to determine compliance, 3) specifies the radiation sources, energy ranges, and the dose equivalent ranges, and 4) specifies the irradiation geometries and extremity phantom designs to be used during the performance testing. The final version of this draft HPSSC standard could be used as a basis for DOE's development of a standard for performance testing of extremity dosimetry systems.

The DOE, Office of Health, has contracted with PNL to conduct a feasibility study to determine the appropriateness of the draft standard for the performance testing of extremity dosimeters from DOE facilities, and to provide recommendations for appropriate testing procedures. Four DOE contractor facilities participated fully in the performance testing study and partial results were obtained from three additional facilities. Six types of ring dosimeters and two types of wrist dosimeters were submitted for testing. This report contains a description of the procedures used for the performance testing study, the results obtained and recommendations for appropriate testing procedures, and for improvement of the draft standard. 


\section{FEASIBILITY STUDY PROCEDURES}

The feasibility study procedures are based on the test procedures provided in the HPSSC draft standard, P/N13.32, "Standard for the Performance Testing of Extremity Dosimeters (Committee Draft VIII)", Apri1 1988. This section provides a description of the test design and a description of the dosimeters submitted for the study. This section also provides the procedures that were used for the dosimeter handling and irradiation, the dose equivalent calculation, and the test evaluation. Deviations from the procedures given in the HPSSC draft standard are discussed.

\section{TEST DESIGN}

The test design of the draft standard is similar to the test designs given in the ANSI N13.11 (ANSI 1983) and the DOELAP standards (DOE 1986). The draft standard specifies seven irradiation categories in which facilities that process extremity dosimeters may receive accreditation. The irradiation categories specified in the draft standard appear in Table 1 along with the sources specified for each category and the energy and dose ranges for each category. The categories include both accident dosimetry (doses of 10 to $500 \mathrm{rad}$ ) and occupational (protection) dosimetry (dose equivalents of 0.25 to $20 \mathrm{rem})$. (a) The categories include high-energy and low-energy photons, beta particles, neutrons, and mixtures. A nearly monoenergetic, low-energy photon source (Category IIIB) and the uranium slab source (Category VB) were included for application to specific environments. These categories were included for use in place of, or in addition to, Categories IIIA and VA, depending on the occupational environment covered by the dosimetry service.

During the feasibility study, the facilities selected the irradiation categories based on the services they provide from the list in Table 1 . The facilities then sent the dosimeters required for the tests to the testing laboratory. The test dosimeters were submitted in three separate groups of

(a) The test range for Category VA was reduced from the range specified in the draft standard $(0.15$ to $20 \mathrm{rem})$ to a range of 0.15 to $10 \mathrm{rem}$ for this feasibility study because of the length of time required to irradiate dosimeters with the sources invoived. 


\section{TABLE 1. Irradiation Categories}

\section{Category}

I. Low-Energy Photons (X Ray)Accident Dosimetry

NIST-Filtered Technique(a) M150

II. High-Energy PhotonsAccident Dosimetry $137 \mathrm{Cs}$

IIIA. Low-Energy Photons (X Ray)General

NIST-Filtered Techniques(a) M30

560

M150

H150

IIIB. Low-Energy Photons (X Ray)-

Plutonium Environments

Monoenergetic

Monoenergetic

$241_{A m}$

IV. High-Energy Photons $137 \mathrm{Cs}$

60 Co

VA. Eeta Particles - General 204 TI (b)

$90 \mathrm{Sr} / 90 \mathrm{r}$ (filtered)

VB. Beta Particles - Slab

Uranium

Natural Uranium

Depleted Uranium

VI. Neutron

$$
2.52 \mathrm{Cf} \text { (moderisted) (c) }
$$

252Cf (unmoderated)

VII. Mixture Categories

III. \& IV.

III. \& V.

IV. \& V

III. \& VI. (d)

IV. \& VI.

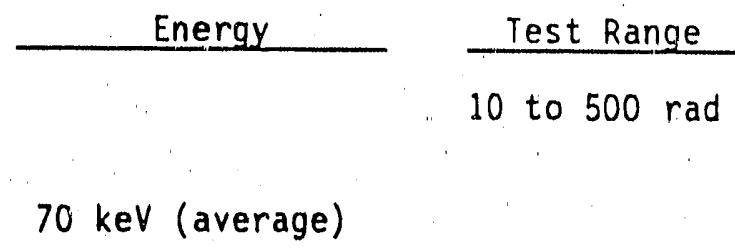

10 to $500 \mathrm{rad}$

$602 \mathrm{keV}$

\subsection{5 to $20 \mathrm{rem}$}

$20 \mathrm{keV}$ (average)
$36 \mathrm{keV}$ (average)
$70 \mathrm{keV}$ (average)
$120 \mathrm{keV}$ (effective)

0.25 to $20 \mathrm{rem}$

15 to $20 \mathrm{keV}$

55 to $65 \mathrm{keV}$

$59 \mathrm{keV}$

$662 \mathrm{keV}$

0.25 to 20 rem

$1.25 \mathrm{MeV}$

$0.76 \mathrm{MeV}$ (maximum)

0.15 to $10 \mathrm{rem}$

$2.3 \mathrm{MeV}$ (maximum)

0.25 to 20 rem

$2.3 \mathrm{MeV}$ (maximum)

$2.3 \mathrm{MeV}$ (maximum)

one energy from each category

(a) NBS Special Publication 250, Appendix C (NBS 1986). The half-value layer and homogeneity coefficient should be adjusted according to the recommendations in ISO 4037 (ISO 1979).

(b) A modified performance algorithm is recommended.

(c) Moderated by $15 \mathrm{~cm}$ of $\mathrm{D}_{2} \mathrm{O}$ (Schwartz and Eisenhauer 1980).

(d) For work environments containing plutonium, use the monoenergetic or 241 Am sources. 
five dosimeters for each of the catey ries selected. The testing laboratory irradiated each group of dosimeters in turn and returned them to the facilities before the next group of dosimeters was sent. The doses were evaluated by the facilities and then submitted to the testing laboratory, where the test results were evaluated against specific performance criteria. At the completion of all three rounds of testing, the test results were reported to the participating facility.

\section{DESCRIPTION OF DOSIMETERS}

Nine DOE facilities that use extremity dosimeters were contacted to determine their interest in participating in this study. All nine of the facilities chose to participate. Eight of the nine facilities processed extremity dosimeters in-house. The ninth facility sent their dosimeters to a commercial facility for processing.

A list of the irradiation categories was sent to each of the facilities and they were requested to choose the categories in which they wished to participate and indicate the type of dosimete: (ring or wrist) that they would submit for the study. Several facilities submitted more than one type of dosimeter. A total of eight types of ring dosimeters and five types of wrist dosimeters were initially submitted. However, of the nine facilities initially participating in the test, two dropped out of the study completely, and three completed only the first two rounds of testing and were unable to participate in the third round.

Although only four facilities completed the entire study, the data from the three facilities that participated in the first two rounds are also included in this report. Thus, results are reported for the six types of ring dosimeters and two types of wrist dosimeters listed in Table 2. Table 2 does not identify dosimeter types by facility, in order to preserve the anonymity of the facilities.

\section{DOSIMETER HANDLING AND IRRADIATION PROCEDURES}

The study was conducted in three rounds. For each round, the participating facilities shipped one group of five dosimeters for each of the categories in which they were participating. Eight to 10 extra dosimeters were 


\section{TABLE 2. Dosimeter Descriptions}

\section{Ring Dosimeters}

- Two-chip dosimeter in plastic ring

- 1 Panasonic(a) UD-807, $\mathrm{Li}_{2} \mathrm{~B}_{407} \mathrm{CC}$ in a plastic ring

- 4 chips positioned at $90^{\circ}$ around a metal ring

- 2 LiF TL-700 chips wrapped in aluminum foil in plastic rings

- One.chip Lif TL-100 in plastic ring

- One-chip TLD in thin plastic holder - tape dosimeter Wrist Dosimeters

- Three-chip wrist dosimeter; 2 Li6f F TL-600 chips and 1 LipF TL-700 chip

- Two-chip LiF TL-100 in a metal case

(a) Division of Matsushita Electric Corporation of America, Secaucus, New Jersey.

sent with each shipment for each type of dosimeter, to be used as controls and spares. Upon receipt, the dosimeters were counted, logged in, assigned an identification number, and organized into groups for irradiation. Dosimeters awaiting irradiation or shipment were stored in the same low-background area. The control dosimeters were stored in an area of low-background radiation while the irradiations were performed.

As specified in the draft standard, the dosimeters were irradiated while placed on phantoms except for those exposed to the uranium source. The uranium exposures were performed by placing the dosimeters directly upon the uranium slab. Two phantom types were specified by the draft standard: one to represent a finger to test ring or hand dosimeters, and one to represent a lower arm or leg to test wrist or ankle dosimeters. The finger phantom was a right circular cylinder constructed of methylmethacrylate with a diameter of $19 \mathrm{~mm}(0.75 \mathrm{in.})$ and a length of $610 \mathrm{~mm}$ (24 in.). Two arm phantom designs were used: one for neutron exposure and one for photon and beta exposures. The arm phantom for the neutron exposures was a right circular cylinder made of solid methylmethacrylate. The neutron arm phantom had a diameter of $73 \mathrm{~mm}$ (2.9 in.) and a length of $610 \mathrm{~mm}(24 \mathrm{in.})$. The arm phantom for the photon 
and beta exposures was constructed of a methylmethacrylate outer cylinder with an aluminum inner cylinder. The aluminum insert for the arm phantom used for photon and beta exposures was $60 \mathrm{~mm}$ (2.4 in.) in diameter and was nested inside the methylmethacrylate tube having an inner diameter of $60 \mathrm{~mm}$ ( $2.4 \mathrm{in.})$ and an oute; diameter of $73 \mathrm{~mm}(2.9 \mathrm{in.})$. The tubes were of the same length and were $457 \mathrm{~mm}$ (18 in.) long. The phantom designs were researched in a study reported by Roberson, Eichner, and Reece (1986).

Irradiations on the finger phantom vere performed, when possible, in sets of five dosimeters. Irradiations on the wrist phantom were performed, when possible, in sets of three dosimeters. The order of the dosimeters on the phantom was alternated each time. No two dosimeters from the same processor were irradiated together. Thus, a suspected misirradiation could be checked by comparing dosimeter results from other processors. An exception was made for Facility $D$, which was unable to send dosimeters during Round 2 due to scheduling conflicts and reader equipment difficulties. These dosimeters were irradiated individually following the Round 3 irradiations.

The draft standard specifies that for each category, except for the category specifically identified as that dealing with radiation mixtures (Category VII), only one type of radiation and one energy spectrum are to be used for all three rounds of a given test. However, for this study, the source used in the multiple-source categories was varied so that the study would identify variations in response to the different sources. The specific source used in each round of the test was randomly selected for each category from the list in Table 1, with the exception of the 241 Am source, which was not available for Category IIIB, and the depleted uranium slab, which was the only source available for Category VB. The random si lection occurred without replacement for categories containing three or more sources. Thus, the same source was selected only once in these categories. The one facility participating in Category VII specified that their dosimeters not be included in mixtures including neutrons. Thus, only mixtures without neutrons were selected for Category VII. 
The method specified in the draft standard (Committee Draft $V$, June 1986) for the selection of irradiation levels was suggested by ANSI N13.11 (ANSI 1983). This process invoives the selection of random numbers, $\rho$, between 0 and 1 . The logarithm of the dose equivalent, $H$, is then calculated as:

$$
\log H=\log (H)_{1}+\rho\left[\log (H)_{u}-\log (H)_{1}\right]
$$

where $(H) I$ and $(H) u$ are the lower and upper limits, respectively, of the test irradiation levels in question. The random selection of the logarithms of the irradiation levels rather than of the levels themselves increases the probability of selecting values near the lower limit of the range.

For collimated beams, the phantom was positioned so that the central beam axis was perpendicular to and passing through the center of the phantom. For uncollimated beams, the ceriter of the phantom was perpendicular to the radial line from the source center. The calculation of the dose took into account the variation in radiation intensity at the position of each dosimeter on the phantom.

Pretest calibration exposures were provided for the neutron category. Also provided was the ratio of a $23-\mathrm{cm}(9-i n$.$) diameter spherical rem meter$ and a $7.6 \mathrm{-cm}\left(3-\mathrm{in}_{.}\right)$diameter sphere covered with $0.03 \mathrm{~cm}(0.010-$ in.) thick cadmium to provide a relative calibration for albedo dosimeters (Griffith et al. 1979). This ratio is 2.70 for unmoderated $252 \mathrm{Cf}$ and 0.31 for the moderated $252 \mathrm{Cf}$ [moderated by $25 \mathrm{~cm}(2.9 \mathrm{in.})$ of $\mathrm{D}_{2} \mathrm{O}$ as reported by Schwartz and Eisenhauer (1980)].

The facilities participating in Categories I, II, and VI (the accident categories and the neutron categories) were given the opportunity to assign dosimeters to these categories before the dosimeters were sent to the testing laboratory. The dosimeters in the remaining categories were chosen at random by the testing laboratory. Thus, the specific dosimeters irradiated in Categories I, II, and VI were known by the facilities when the dosimeters were returned for evaluation. The remaining dosimeters were packaged together so that the facilities would not know which dosimeters were irradiated in Categories III, IV, V, or VII. This was done in response to a previous draft of 
the standard that indicated that processors should not know the identification of dosimeters irradiated in Catogories III, IV, V, and VII. After receiving the dosimeters, the facilities evaluated the dosimeters and reported the dose to the testing laboratory. After the results were received by the testing laboratory, a letter was sent to each of the facilities listing the identification of each dosimeter that was irradiated in Categories III, IV, V, and VII and requesting that they reanalyze their results based on this information. The source and the irradiation level used were not identified for any of the categories except for Category VI, for which the source (moderated versus unmoderated $252 \mathrm{Cf}$ ) was specified. Following receipt of the final results for Round 1, a letter was sent to the facilities providing them with the results of the Round 1 irradiations and requesting that they use this information during the evaluation of the doses for the subsequent rounds of testing. The dosimeters irradiated in Categories III, IV, $V$ and VII were again not identified initially following Rounds 2 and 3. However, they were identified to the facilities after the testing laboratory had received the initial set of results, and the facilities were requested to re-evaluate their results based on this information.

\section{DOSE EQUIVALENT CALCULATION PROCEDURES}

The dose equivalent assigned to dosimeters exposed to photons was calculated using the exposure-to-dose conversion factors $\left(C_{x}\right)$ shown in Table 3 (Roberson, Eichner, and Reece 1986). The shallow dose equivalent $\left(H_{s}\right)$ or absorbed dose $\left(D_{S}\right)$ for the photon irradiations using a sealed source (Categories II and IV) was calculated as:

$$
H_{s}=Q C_{x} \dot{x}_{a i r} t
$$

or

$$
D_{s}=C_{x} \dot{x}_{\text {air }} t
$$


where $Q$ the quality factor, defined as $1.0 \mathrm{rem} / \mathrm{rad}(1.0 \mathrm{~Sv} / \mathrm{Gy})$ (assumed for calculation of dose to the extremities) although not defined for extremities

$C_{x_{1}}$ = the expostire-to-dose conversion factor for shallow dose(s) in $\mathrm{rad} / \mathrm{R}$

$\dot{x}_{a j r}=$ exposure rate in air at the point of irradiation

$t=$ irradiation time

For $x$-ray exposures (Categories I and III) referenced to an unsealed monitor ionization jhamber the shallow dose equivalent $\left(H_{s}\right)$ or absorbed dose $\left(D_{s}\right)$ was calculated as:

$$
H_{S}=Q C_{X} T M C_{T P}
$$

or

$$
D_{S}=C_{X} T M C_{T P}
$$

TABLE 3. Exposure-to-Dose Conversion Factors $\left(C_{X}\right)$ for Extremity Phantoms at Shallow Dose (Roberson, Eichner, and Reece 1986)

\section{Conversion Factors $(C \times)$, rad/R

Arm/Leg Phantom Finger Phantom

NIST Filtered X-Ray Techniques

$\begin{array}{lll}\text { M30 } & 0.99 & 0.95 \\ \text { S60 } & 1.05 & 0.99 \\ \text { M150 } & 1.14 & 1.01 \\ \text { H150 } & 1.13 & 1.02\end{array}$

K-Fluorescence $X$-Ray

Techniques

by Energy, keV

$\begin{array}{lll}16 & 0.96 & 0.92 \\ 23 & 1.00 & 0.96 \\ 31 & 1.03 & 0.98 \\ 40 & 1.06 & 0.99 \\ 59 & 1.13 & 1.00 \\ 75 & 1.14 & 1.01 \\ 98 & 1.15 & 1.02\end{array}$

Gamma Ray Sources

$\begin{array}{rll}137 \mathrm{Cs} & 1.02 & 0.98 \\ 60 \mathrm{Co} & 1.00 & 0.98\end{array}$


where $Q$ and $C_{x}$ are as defined above

$T=$ exposure-per-charge calibration factor for the monitor chamber at the standard temperature and pressure

$M=$ reading of the monitor chambei in units of charge

$C_{T P}=$ temperature and pressure correction factor for the monitor chamber

The shallow dose equivalent $\left(H_{s}\right)$ assigned to dosimeters exposed to beta-particle fields (Category $V$ ) was calculated using the equation:

$$
H_{s}=\dot{D}_{t}(d) t Q C_{t r a n s}
$$

where $\dot{D}_{t}(d)=$ absorbed dose rate at the calibration depth $d$,

$t=$ time

$Q=$ the quality factor, defined as $1 \mathrm{rem} / \mathrm{rad}$ ( $1 \mathrm{~Sv} / \mathrm{Gy}$ ) (assumed for the calculation of dose to the extremities).

$C_{\text {trans }}=$ transmission factor defined as

$$
C_{\text {trans }}=\frac{\dot{x}\left(7 \mathrm{mg} / \mathrm{cm}^{2}\right)}{\dot{x}(d)}
$$

where $\dot{x}$ is the relative extrapolation chamber signal, corrected for temperature and pressure and $d$ is the original calibration depth.

Calculation of the free-field dose equivalent for dosimeters exposed to 252Cf sources (Category VI) uses the following formula for the unmoderated source (Schwartz and Eisenhauer 1982):

$$
H_{d}=\frac{N C_{U N} t 3600}{4 \pi r^{2}}
$$

where $H_{d}=$ the deep dose equivalent in a slab phantom

$$
N=\text { the neutron emission rate }(n / \mathrm{sec})
$$

CUN $=$ the deep dose-equivalent conversion factor for unmoderated 252. Cf $\left(3.33 \times 10^{-5} \mathrm{mrem}-\mathrm{cm}^{2} / \mathrm{n}\right)$ 


$$
\begin{aligned}
t & =\text { the time in hours } \\
3600= & \text { the number of seconds in an hour, } \\
r= & \text { the calibration distance (from the source center to the front } \\
& \text { surface of the phantom, } \mathrm{cm}) .
\end{aligned}
$$

The shallow dose equivalent in the extremity phantom is assumed to be equal to the deep dose equivalent in a slab phantom for the calculation of the free-field dose equivalent, for dosimeters exposed to $252 \mathrm{Cf}$ sources.

For the moderated source, the following formula was used:

$$
H_{d}=\frac{N C_{M} t(3600)(0.885)}{4 \pi r^{2}}
$$

where $C_{M}=$ the deep dose-equivalent conversion factor for moderated $252 \mathrm{cf}\left(9.08 \times 10^{-6} \mathrm{mrem}-\mathrm{cm}^{2} / \mathrm{n}\right)$

$\begin{aligned} 0.885= & \text { a factor that allows for the loss of the number of neutrons } \\ & \text { inoderated below the cadmium cutoff as a result of the cadmium } \\ & \text { surrounding the } \mathrm{D}_{2} 0 \text { sphere }\end{aligned}$ and $H_{d}, N, t, r$ and the factor 3600 are as defined above.

The current flux-to-dose-equivalent conversion factors as specified in regulations and recommendations of the National Council on Radiation Protection and Measurements (NCRP 1971) are derived from the maximum value of dose equivalent in a $30-\mathrm{cm}-(11.8-i n .-)$ diameter cylindrical torso phantom. These values include secondary charged particles from neutron interactions as well as contributions from garnma rays from the absorption of neutrons by hydrogen atoms. Although the cylindrical torso phantom model is not applicable for the extremities, the flux-to-dose equivalent rate conversion factors recommended by the NCRP (1971) were applied in this study in the absence of more pertinent information.

Typical values for the photon component of $252 \mathrm{Cf}$ are $7 \%$ of the neutron dose equivalent for unmoderated irradiations (Plato and Hudson 1980) and $18 \%$ for moderated irradiations (McDonald et al. 1983). These values were verified for PNL's irradiation facilities using neutron sources calibrated directly to the National Institute of Standards and Technology (NIST) sources and the values were supplied to the processors. Because pre-test 
calibrations were given, corrections were not applied to the neutron dosimeter readings for scattering.

The radiation sources used in this study were calibrated directly or indirectly to NIST sources. The uncertainty in the assigned dose equivalent was calculated as given in Appendix A. The calculated uncertairity did not exceed $5 \%$ (excluding uncertainties in the dose-equivalent conversion factors and in the photon component of the neutron irradiations). (a) The calculated uncertainty inclures the following: the uncertainty in the source standardization, the uncertainty in positioning the dosimeter, the uncertainty in timing the exposure, and the uncertainty due to scattered radiations. The random uncertainties (positioning of the dosimeter, timing of the exposure, and source calibration) are summed quadratically. The $* 5 \%$ limit applies to the linear sum of systematic uncertainties and one standard deviation calculated for the random uncertainties.

Dose-rate uniformity measurements were performed with the phantoms in place to determine the useful exposure area for each source. Positiondependent correction factors were used to comply with the uncertainty limits.

\section{TEST EVALUATION PROCEDURES}

The dosimeter performance was evaluated using the performance criterion specified in the draft standard. The performance criterion used in the draft standard is based on the criterion derived in the DOELAP standard (DOE 1986). A similar performance criterion was specified in ANSI N13.11-1983 (ANSI

1983). The performance criterion is:

$$
|B|+S \leq L
$$

where $B=$ bias,

$$
S=\text { the standard deviation, and }
$$

(a) Since the dose-equivalent conversion factors are used by the testing laboratory and the participants, no irradiation uncertainty is associated with its use. The values used for the photon component of the neutron irradiations were also provided to the processors. 
$L=$ the tolerance level.

The performance quotient, $P_{i}$, is a measure of the agreement between the reported dose equivalent (or absorbed dose) and the true or delivered dose equivalent (or adsorbed dose):

$$
p_{i}=\frac{\left[x_{i} \text { (reported) }-x_{i} \text { (delivered) }\right]}{x_{i} \text { (delivered) }}
$$

where $x_{i}$ is the absorbed dose or dose equivalent. The performance quotient can also be termed the relative bias.

The bias, $B$, is the average of the performance quotients, $P_{i}$ (or an average of the relative biases) of the dosimeters tested:

$$
B=\frac{1}{n} \sum_{i=1}^{n} P_{i}
$$

The bias provides an estimate of the accuracy of the dosimeters (how close the reported dose is to the delivered dose).

The standard deviation, $S_{1}$ is a measure of the precision of the performance quotients, that is, of how closely the performance quotients (relative biases) are grouped together:

$$
S=\sqrt{\frac{\sum_{i=1}^{n}\left(P_{i}-B\right)^{2}}{n-1}}
$$

The standard of performance, i.e., the tolerance level giver in the HPSSC draft standard, was based upon recommendations in the International Commission on Radiation Units and Measurements (ICRU) Report 20 (ICRU 1971) and in NCRP Report 57 (NCRP 1978). These reports recommend a $30 \%$ limit on the uncertainty of the dose equivalent in the vicinity of the maximum permissible dose (MPD). For extremities, the maximum permissible dose is given in 
DOE Order 5480.11 (DOE 1988) as $50 \mathrm{rem} / \mathrm{yr}$. At one-quarter of the MPD, the NCRP allows as acceptable, a lower level of accuracy (e.g., a factor of 2). The ICRU suggests a factor of 3 on the uncertainty for doses of one-tenth the MPD. At higher doses, such as may occur during accidents, an accuracy of $\pm 20 \%$ was considered appropriate by the NCRP. Early drafts of ANSI N13.11 included different performance criteria for various levels of dose. However, performance tests of whole-body dosimeters indicated that this was unnecessary over the typical range of dose equivalents (ANSI 1983). The time period over which the accuracy is achieved was not specified by the ICRU or by the NCRP. Thus, the performance criterion adopted in the draft standard approximately represents the requirement that the annual assignment of dose equivalent should be within $30 \%$ of the conventionally true value for $95 \%$ of the personnel receiving in excess of one-tenth of the maximum permissible dose equivalent. The derivation of the criterion assumed a dosimeter exchange rate of four times per year and approximately uniform occupational exposures.

Because of the uncertainty in the assigned dose equivalent (which did not exceed $\pm 5 \%$, excluding uncertainties in the dose-equivalent conversion factors and the photon component of the neutron irradiations), the performance criterion adopted in the draft standard was set to:

$$
|B|+S \leq 0.35
$$

where $B$ is the bias and $S$ is the standard deviation as given above, and 0.35 includes the allowed $30 \%$ error in the assignment of the delivered dose equivalent (or abscrbed dose) and the $5 \%$ maximum uncertainty in the delivered dose equivalent (or absorbed dose). Because of technical and practical limitations of current dosimeter designs, the test for the low-energy beta source (204TI) listed in Table 1 was set to:

$$
|B|+S \leq 0.40
$$

A discussion of the appropriateness of this performance criterion is given later. 


\section{RESULTS}

The average of the relative biases (B) and the standard deviation (S) were calculatej for each model of dosimeter submitted for testing in each of the categories. The calculations were performed separately for each round of testing (five dosimeters per round in each category) in order to compare the results obtained in each round. The sum of the absolute value of the bias and the standard deviation was calculated for comparison against the tolerance level designated by the draft standard for the performance criterion.

The results of the dosimeter performances(a) are plotted in Figures 1 and 2 for ring dosimeters and in Figures 3 and 4 for wrist dosimeters: Appendix $B$ contains the performance data organized by irradiation category for each type of dosimeter tested in this study. The bias and standard deviation for ring dosimeters are shown on separate axes in Figure 1. The sum of the absolute value of the bias and the standard deviation $(I B \mid+S)$ for the ring dosimeters is given in Figure 2. Figure 3 shows the bias and standard deviation of the wrist dosimeters, and Figure 4 gives the sum of the absulute value of the bias and the standard deviation $(I \mathrm{~B} \mid+S)$ for the wrist dosimeters. The radiation sources used in each round for each category are identified along the $x$-axis. The data points are coded $A$ through $H$ to correspond to each of the processors (Facilities $C$ and I dropped out of the study). The dashed line placed at 0.35 (in Figures 2 and 4 ) represents the tolerance level specified in the draft standard. A second dashed line placed at 0.40 above the $204 \mathrm{Tl}$ label (in Figures 2 and 4 ) represents the tolerance level for the low-energy beta source (204T1) used in Category VA.

Data points that are off-scale in the positive direction are identified above each of the graphs. For the ring dosimeters (Figures 1 and 2) for Facility $F$, the off-scale results in Categoi: IV appeared to result from a misplaced decimal point for one of the readings. The reasons for the offscale results from other facilities were not readily apparent.

(a) The results shown in the graphs and given in the text are based on an analysis of the dosimeter performance on a per round basis, rather than combining the results for all three rounds. 

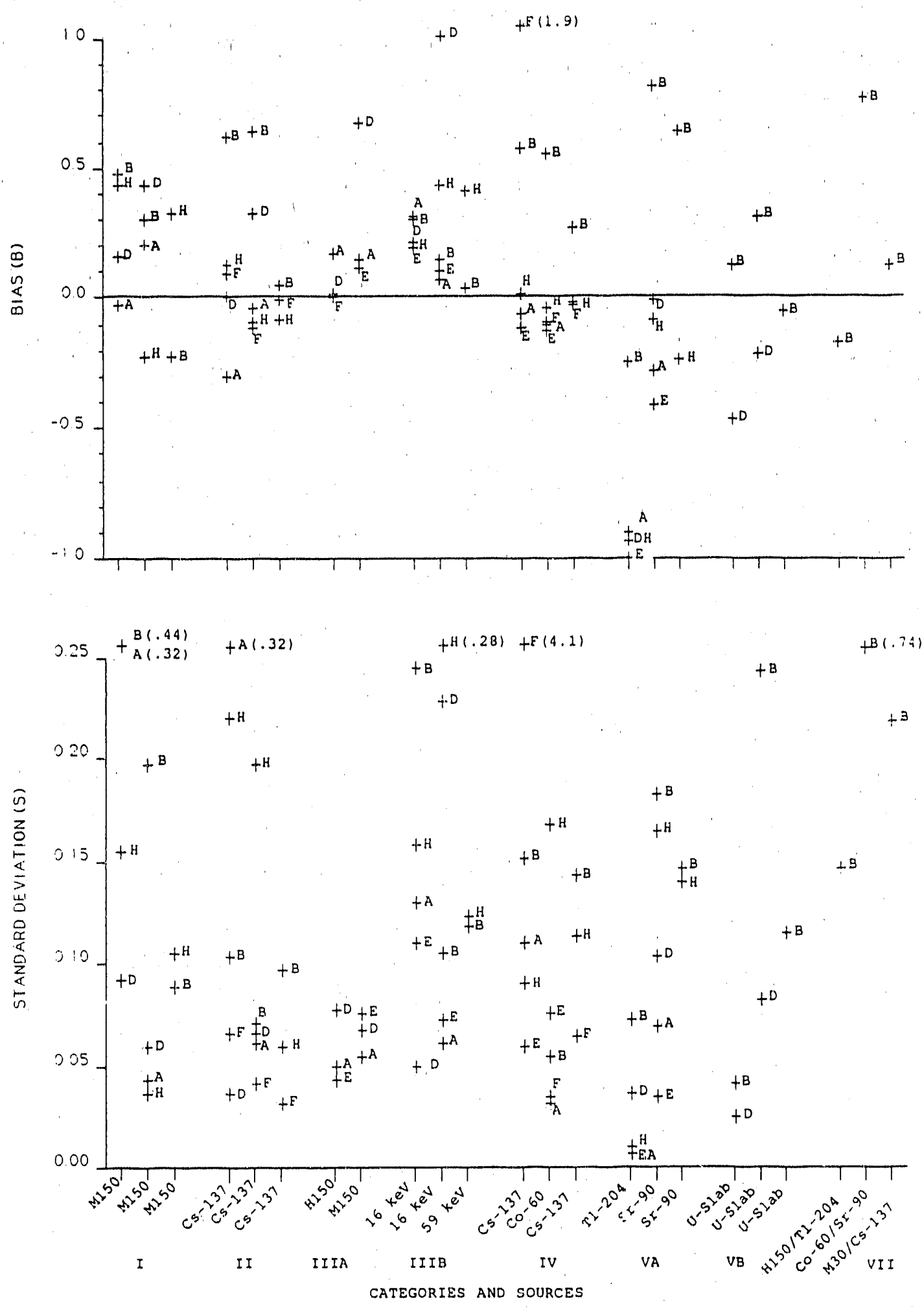

FIGURE 1. Bias and Standard Deviation (S) for Ring Dosimeters 


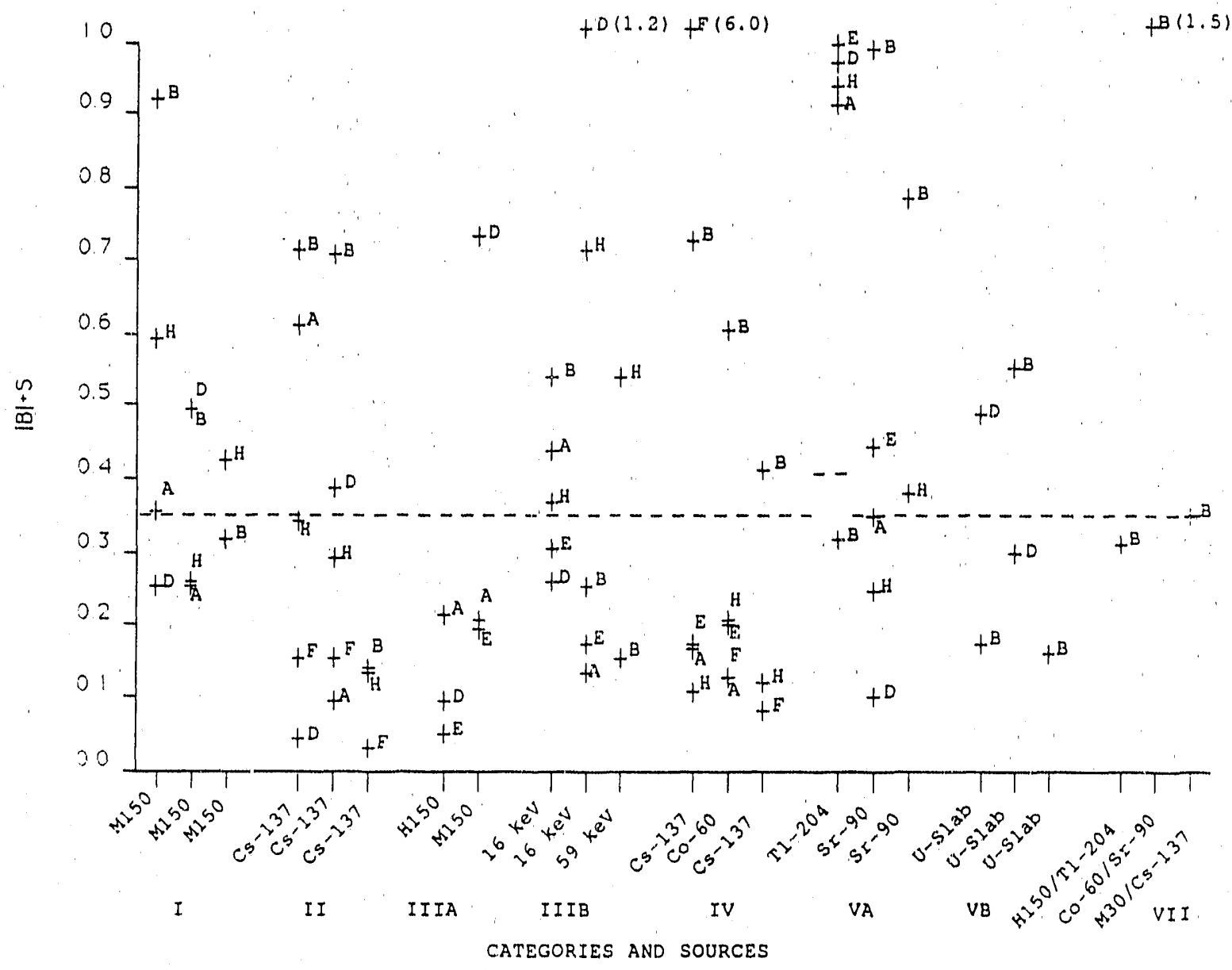

FIGURE 2. Surmary of Performance $(|B|+S)$ for Ring Dosimeters 

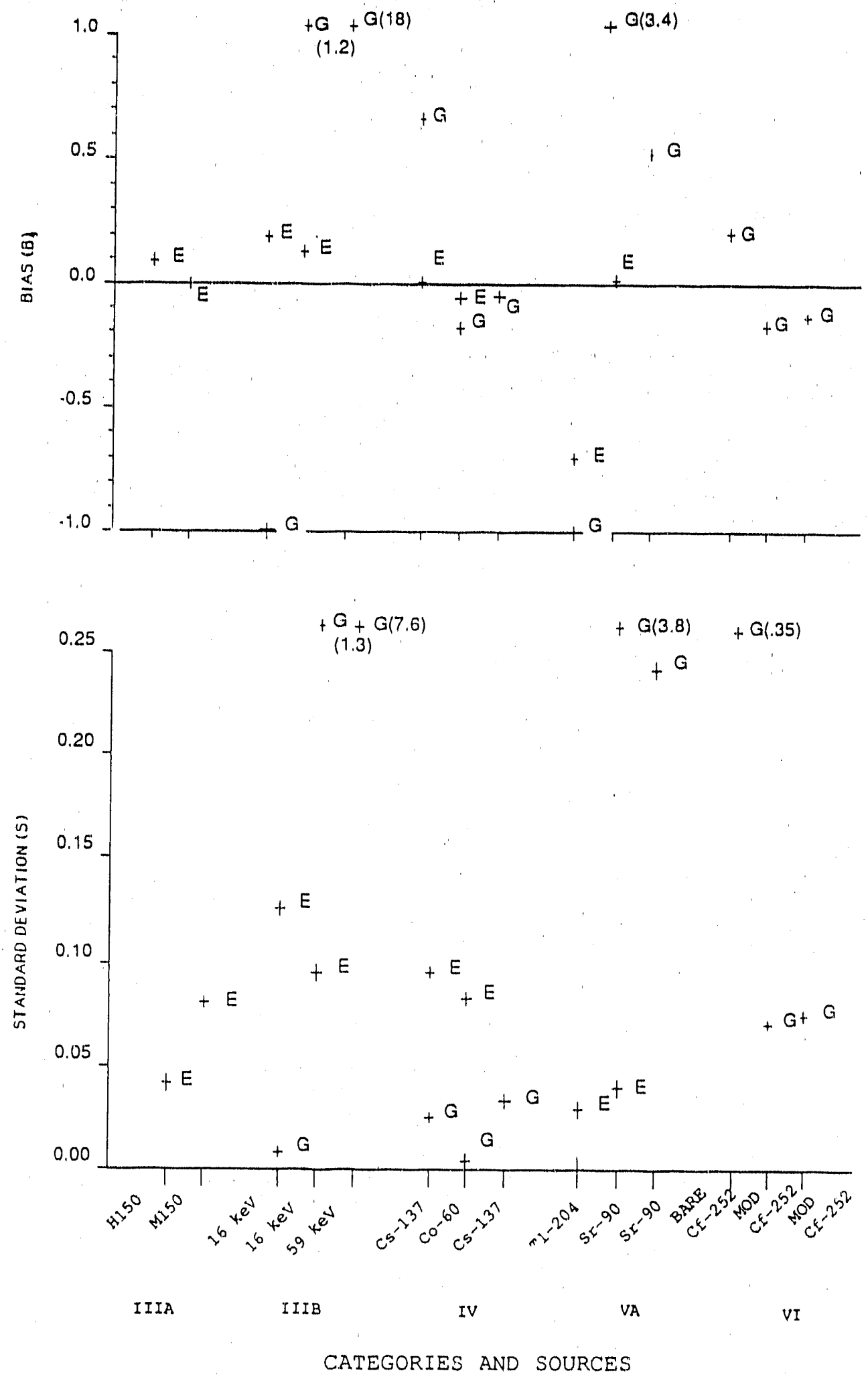

FIGURE 3. Bias (B) and Standard Deviation (S) for Wrist Dosimeters 


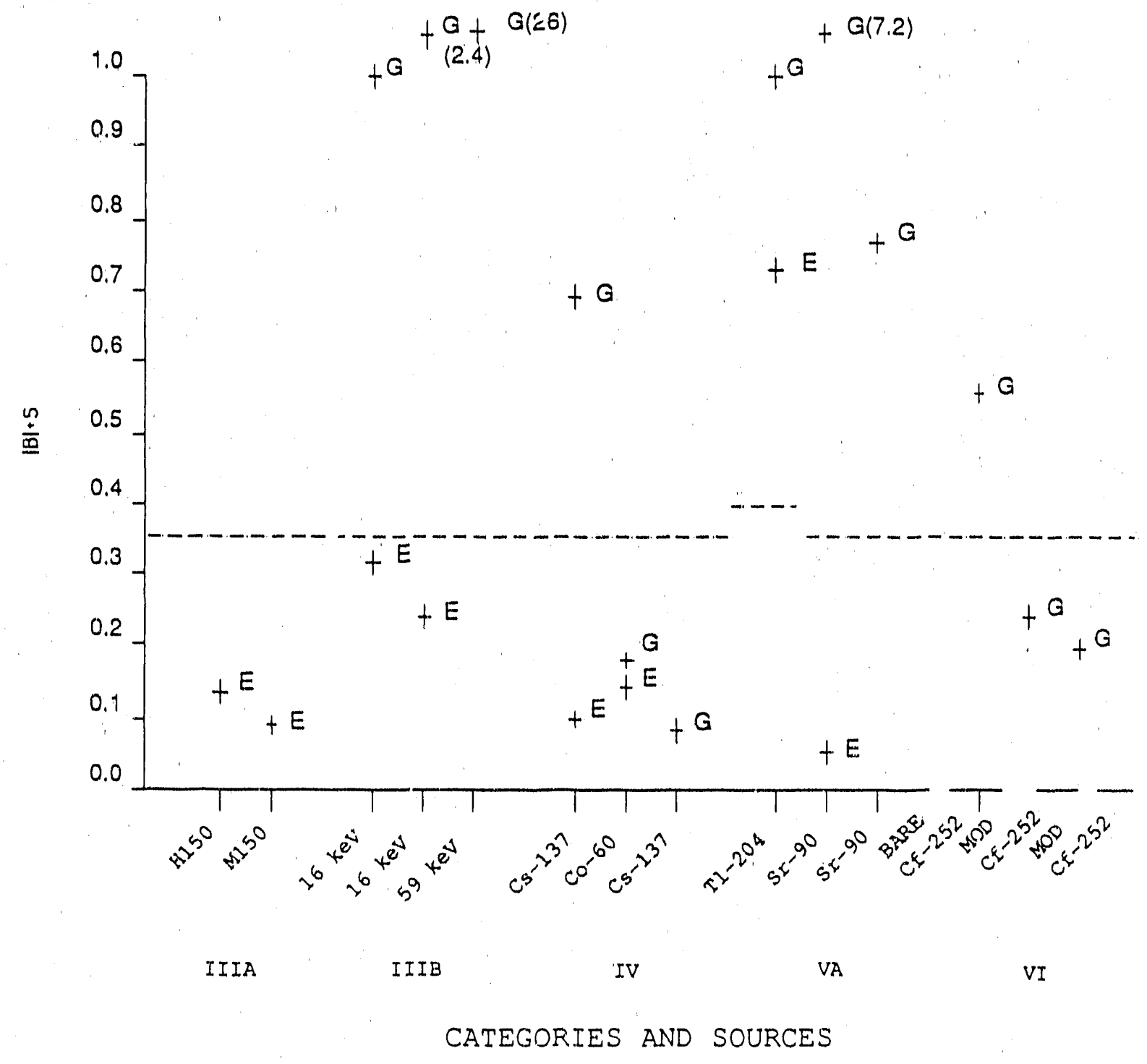

FIGURE 4. Summary of Performance $(|\mathrm{B}|+\mathrm{S})$ for Wrist Dosimeters 
For the ring dosimeters, the best performances were exhibited in Category IIIA (low-energy photons, general) with the dosimeters passing the test at the 0.35 tolerance level over $80 \%$ of the time and in Categories II (highenergy photons, accident dosimetry) and IV (high-energy photons, protection dosimetry) with the dosimeters passing the test at the 0.35 tolerance level almost $70 \%$ of the time (Figure 2). The worst performance was observed in Category VA (beta particles, general), in which the dosimeters passed only $33 \%$ of the time. The only marked variation in the results from different sources within the same category was in Category VA (beta particles, general), where dosimeters met the tolerance level $43 \%$ of the time when exposed to the $90 \mathrm{Sr} / 90 \mathrm{Y}$ source, and only $20 \%$ of the time exposed to the $204 \mathrm{Tl}$ source. This is to be expected because of the difficulties in discriminating between low-energy betas.

The number of wrist dosimeters participating in the feasibility study was small as a result of facilities dropping out of the study or not submitting a complete set of results. For this reason, no results were obtained for Category I (low-energy photons, accident dosimetry), Category II (highenergy photons, accident dosimetry), Category VB (beta particies, slab uranium), or Category VII (mixtures). Because data was obtained from only two types of wrist dosimeters, it was difficult to appropriately compare the results between categories or between sources within categories.

Figures 2 and 4 show that the results are processor or facility dependent. For the ring dosimeters, three of the facilities passed at least $75 \%$ of the time for those categories in which they were tested. The other three facilities passed less than $55 \%$ of the time. The threa ring dosimeter types that had the highest passing rates were a one-element dosimeter, a twoelement dosineter, and a four-element dosimeter. For wrist dosimeters, one facility passed $86 \%$ of the time and the other facility passed oniy $33 \%$ of the time.

The results shown for finger rings in Figure 1 indicate that the major cause of not passing the performance test is a result of the bias, rather than the staidard deviation. For ring dosimeters, the average standard deviation is 0.12 , while the average bias (calculated using the absolute value of 
each bias) is 0.28 . (a) For wrist dosimeters (Figure 3), the average standard deviation is 0.08 , while the average bias (calculated using the absolute value of each bias) is 0.30 . (a) These results indicate that while the precision of the extremity dosimeters is good, the accuracy needs improvement.

Overal1, 58\% of the time the ring dosimeters passed, and 55\% of the time the wrist dosimeters passed at the tolerance level given in the draft standard. This is comparable to passing rates of approximately $60 \%$ for both ring and wrist dosimeters in a similar study performed for the U.S. Nuclear Regulatory Commission (Harty, Reece, and Hooker 1987).

Following the initial analys is of the dose for each round of testing, the facilities were notified of the dosimeters irradiated in Categories III, IV, $V$ and VII and asked to reevaluate the dose on the dosimeters (the dosimeters irradiated in Categories I, II and VI were identified to the facilities when the dosimeters were returned from the testing laboratory). Figures 5 and 6 show the initial results (designated by the symbol "+") compared to the reevaluated results (designated by the symbol "0"). Some facilities did not take the opportunity to change their results. When results were changed, the changes were not necessarily an improvement. Overall, there was a decrease in the passing rate following disclosure of the categories in which the dosimeters were irradiated. The passing rate decreased by $5 \%$ for the rings and $22 \%$ for the wrists. The decreased passing rate is due in part to continued uncertainty regarding the source that was used for the irradiations. The sources used during the irradiations were not identified to the facilities, and, in Category VA, for example, it was apparent that corrections were made in the wrong direction.

The results from Round 1 were disclosed to the facilities following that round of testing so that the facilities could use the results in their analysis of the dose delivered to the dosimeters during Rounds 2 and 3 . The data, as shown in Figures 2 and 4 do not show any improvement in the results from Round 2 and 3 over the results from Round 1 although source related improvement could be observed in Category VA.

(a) Outliers with both biases and standard deviations greater than 1.0 were not included in these calculations. 

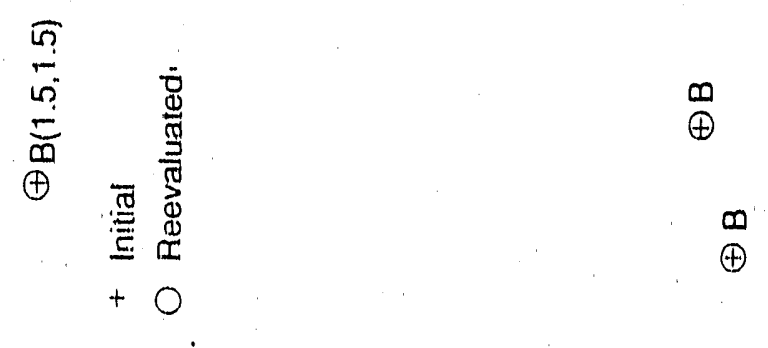

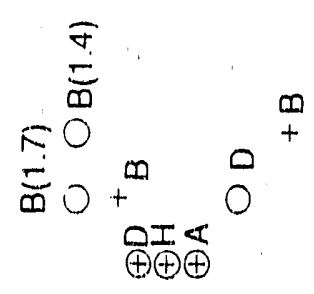
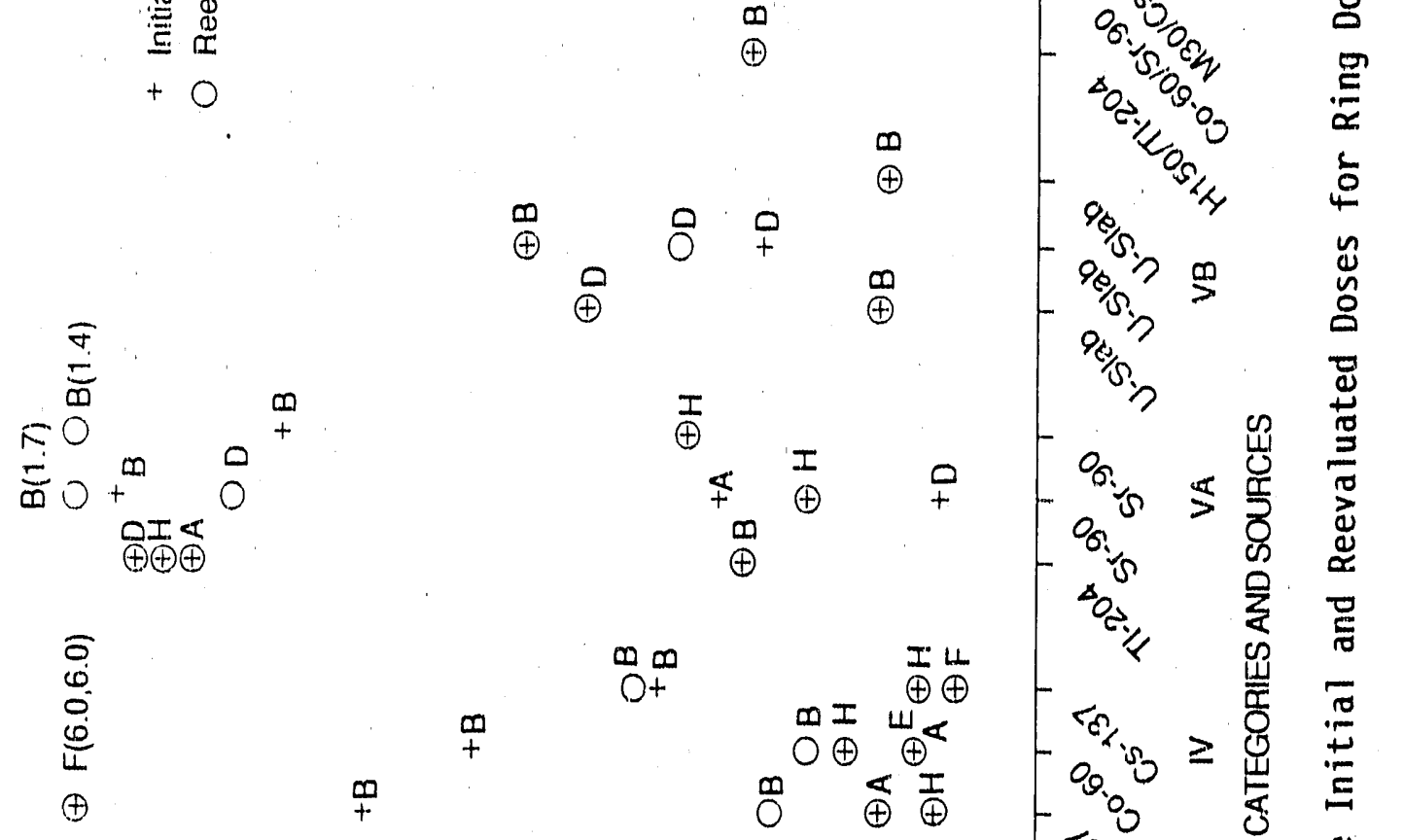

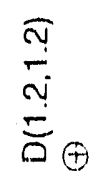

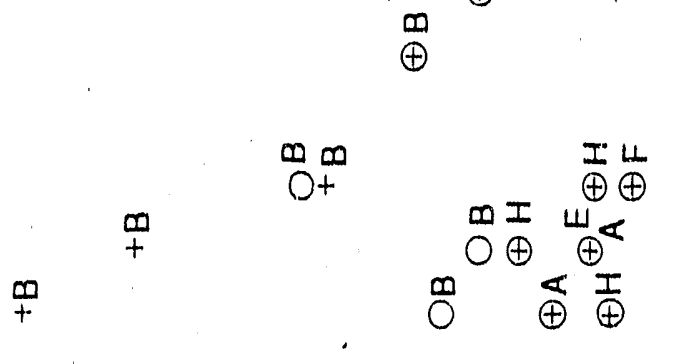

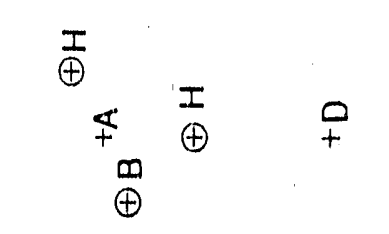

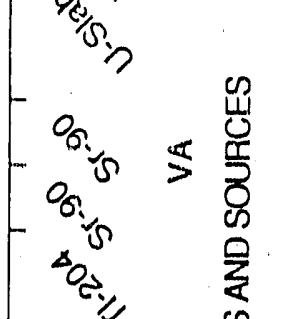

总 


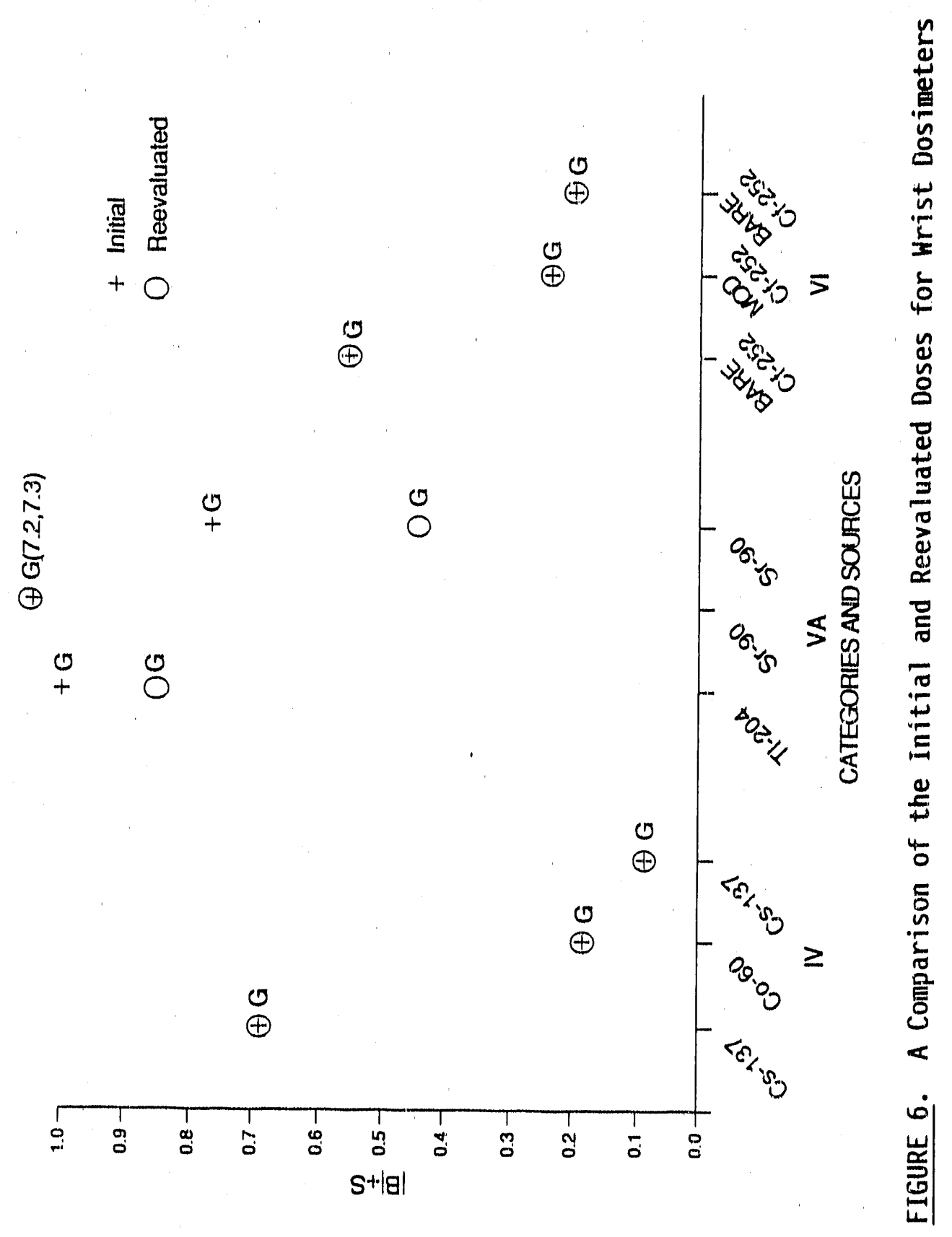


Before a standard can be used to conduct performance testing of extremity dosimeter processors, it must appropriately reflect the current use of extremity dosimeters in such a way as to promote cierall worker safety. The information from the performance test study discussed in this reprit is used to provide recommendations for changes in the draft standard. The recommendations are divided into two areas: 1) the irradiation categories and 2) the performance criterion.

\section{IRRADIATION CATEGORIES}

As a result of the information and experience obtained during the feasibility study, the following changes in the irradiation categories are recommended:

- Results from Category VA (beta particles, general) indicate that the dosimeters that were submitted for this study were unable to discriminate between low-energy beta radfations, such as $204 \mathrm{Tl}$, and higher energy beta-radiations, such as $90 \mathrm{sr} / 90 \mathrm{Y}$. Although, multichip dosimeters can be designed to distinguish between low-energy and high-energy beta radiations, the dosimeters submitted in this study had difficulty discriminating between the two. For this reason, a concept similar to that employed by DOELAP (DOE 1986) is recommended. This involves dividing Category VA into three parts (designated $V A, V B$, and $V C$ ), in which Categories VA (204TI source) and $V B(90 \mathrm{Sr} / 90 \mathrm{Y}$ source) are for processors who do not need to discriminate between energies, and Category $V C(204 \mathrm{Tl}$ and $90 \mathrm{Sr} / 90 \mathrm{Y}$ sources) is for facilities whose environments require that they discriminate between energies.

- Neutron exposures to the extremities present a special problem. As discussed previously, current flux-to-dose-equivalent conversion factors specified in regulations and recommendations of the NCRP are derived from the maximum value of dose equivalent in a $30 . \mathrm{cm}$ (12-in.) diameter cylindrical torso phantom. These values include secondary charged particles from neutron interactions as well as contributions from gammo rays from the absorption of neutrons by hydrogen atoms. The cylindrical torso phantom model and corresponding flux-to-dose equivalent conversion factors, however, are not applicable for the extremities (although in general the fluxto-dose equivalent conversion factor for the torso phantom wauld give a conservative overestimate of the dose to the extremities). Although appropriate and realistic flux-to-dose-equivalent conversion factors have not yet been derived for the extremities, the extremities of workers at DOE and DOE contractor facilities are being exposed to neutron fields. An appropriately chosen interim 
value could be used during feasibility and pilot study programs, which would be replaced by a calculated and experimentally tested flux-to-dose-equivalent conversion factor before the standard is finalized and before performance testing is required.

- The upper value for the test range for non-accident (protection) categories should be reduced from 20 rem to 10 rem. This recommendation is made for three reasons: 1) extremely long exposure times are necessary to obtain a dose of 10 to 20 rem for some of the sources and are especially burdensome to the testing laboratory for the amount of information obtained, 2) information obtained during the survey of extremity practices at DOE facilities (Harty, Reece, and MacLellan 1986) indicated that most extremity dosimeters receive doses of less than $10 \mathrm{rem}$, and 3 ) the lower limit of the accident categories was already set at 10 rem.

\section{PERFORMANCE CRITERION}

The performance criterion, including the magnitude of the tolerance level, dictates the stringency of the performance testing. The higher the tolerance level, the less stringent the performance testing and the larger the number of processors that will meet the performance criterion.

The current tolerance level given in the draft standard was derived to fulfill the goal that the annual assigrment of dose equivalent should be within $30 \%$ of the conventionally true value for $95 \%$ of the personnel receiving in excess of one-tenth of the maximum permissible dose equivalent. The derivation of the criterion assumed a dosimeter exchange rate of four times per year and approximately uniform occupational exposures. Information obtained in a previous report (Harty, Reece, and MacLellan 1986) indicates that dosimeter exchanges occur primarily on a monthly basis or on a per-job basis, although other facilities exchange dosimeters quarterly, biweekly or daliy. The dose rate received on the dosimeter varies with the job being performed. In many cases the doses will not be uniform during the year. Thus, the original basis for determining the tolerance level may not be appropriate.

The dosimeters submitted for this study were tested against the tolerance level given in the HPSSC draft standard $(0.35 ; 0.40$ for 204 T1). Using this tolerance leve1, 58\% of the time the ring dosimeters passed and 55\% of the time the wrist dosimeters passed. Although it is possible, and even likely, that continued testing could produce a higher passing rate, it 
should be noted that extremity dosimeters are generally more simplistically designed (especially ring dosimeters), less well developed and less frequently used than whole body dosimeters. Even though further performance testing may, raise the passing rate, a limit as restrictive as that used for whole body dosimeters may not be consistent with the less advanced stage of development in extremity dosimeters. In addition, a more restrictive limit would not be necessary from the aspect of health effects to a worker because of the lower stochastic risk to the extremity as opposed to the whole bodj. Only one testing criterion was used in this study. Consideration should be given to other tolerance levels or testing criterion if continued studies indicated this was appropriate. For example, individual limits could be imposed on the bias and standard deviation, or the tolerance level could be raised initially and then lowered following several years of testing if it was deemed appropriate based on test results. Consideration should also be given to identifying the irradiation sources to the processors during the testing in order to provide consistency with the more simplistic design of extremity dosimeters and how extremity dosimeters are used under field conditions. 
Using the performance criterion and tolerance level given in the draft standard (HPSSC P/N13.32, "Standard for the Performance Testing of Extremity Dosimeters," April 1988), the passing rate for ring dosimeters was $58 \%$ and for wrist dosimeters was 55\%. No facility passed in every category that they entered. The results indicated that the best performances were in Category IIIA (low-energy photons, general) for ring dosimeters, with the ring dosimeters passing the performance criterion over $80 \%$ of the time. The worst performance for ring dosimeters was observed in the beta particle category (Category VA) with the ring dosimeters meeting the performance criterion $33 \%$ of the time. The greatest amount of variation in the results from different sources within the same category was found in Category VA (beta particles, general) where the ring dosimeters met the tolerance level more often when exposed to $90 \mathrm{Sr} / 90 \mathrm{Y}$ than to $204 \mathrm{Tl}$. Because data was obtained from only two types of wrist dosimeters, it was difficult to appropriately compare the results between categories or between sources within categories.

The overall results indicate that there is a need to incorporate performance testing of extremity dosimeters into DOELAP in order to ensure that DOE facilities appropriately measure extremity dose. However, the results also indicated that the following changes should be made to the HPSSC draft standard before it is finalized and used to accredit DOE facilities that process extremity dosimeters:

- Category VA should be divided into three subcategories because of the difficulties in measuring low-energy betas. The subcategories would be designated $V A, V B$, and $V C$, where subcategories $V A(204 T 1$ source) and $\mathrm{VB}$ ( $90 \mathrm{Sr} / 90 \mathrm{Y}$ source) would be used for processors who do not need to discriminate between the two energies, ard Category VC $(204 \mathrm{Tl}$ and $90 \mathrm{Sr} / 90 \mathrm{Y}$ sources) would be used for facilities where mixed beta environments exist, thus requiring that they discriminate between these energies.

- Because appropriate flux-to-dose equivalent conversion factors have not been derived for neutrons, an appropriately chosen interim value should be used in the neutron category during feasibility and pilot study programs. The interim value would be replaced by calculated and experimentally tested flux-to-dose-equivalent conversion factors before the standard is finalized. 
- The upper value for the test range for non-accident (protection) categories should be reduced from 20 rem to 10 rem to avoid unnecessarily long exposure times, to match the lower limit of the accident categories and to be more realistic when compared with actual dose levels at DOE facilities.

- Consideration should be given to identifying the irradiation sources to the processor. This would provide consistency with actual use of extremity dosimeters under field conditions. 


\section{REFERENCES}

American National Standards Institute (ANSI). 1983. American Natiorial Standard for Dosimetry - Personnel Dosimetry Performance - Criteria for Testing. ANSI N13.11-1.983. New York.

Carlson, R. D., and Gese11, T. F. 1986. The Department of Energy Laboratory Accreditation Program in Personnel Dosimetry: Results of the Pilot Performance Test. DOE/ID-12104, U.S. Department of Energy, Idaho Operations Offices, Idaho Falls, Idaho.

Code of Federal Regulations (CFR). 1981. 10 CFR Part 20, "Standards for Protection Against Radiation."

Griffith, R. V., D. E. Hankins, R. B. Gammage, L. Tommasino, and R. V. Wheeler. 1979." "Recent Developments in Personnel Neutron Dosimeters - A Review." Health Physics 36:235-260.

Harty, R., W. D. Reece, and J. A. MacLellan. 1986. Extremity Dosimetry at U.S. Department of Energy Facilities. PNL-5831, Pacific Northwest Laboratory, Richland, Washington.

Harty, R., W. D. Reece, and C. D. Hooker. 1987. Performance Testing of Extremity Dosimeters. NUREG/CR-4959, U.S. Nuclear Regulatory Commission, Washington, D.C.

International Commission on Radiation Units and Measurements (ICRU). 1971. Radiation Protection Instrumentation and Its Application. ICRU Report No. 20, ICRU Publications, Washington, D.C.

International Organization for Standardization (ISO). 1979. $X$ and $x$ Reference Radiations for Calibrating Dosimeters and Dose Ratemeters and for Determining Their Response as a Function of Photon Energy. ISO 4037, UDC 535-34-36:53.089.6, Geneva, Switzerland.

McDonald, J. C., R. V. Griffith, P. Plato and J. Miklos 1983. Measurements of Gamma-Ray Dose from a Moderated 252 Cf Source. NUREG/CR-2 957 , PNL-4590, Pacific Northwest Laboratory, Richland, Washington.

National Council on Radiation Protection and Measurements (NCRP). 1971. Protection Against Neutron Radiation. NCRP Report No. 38, NCRP Publications, Washington, D.C.

National Council on Radiation Protection and Measurements (NCRP). 1978. Instrumentation and Monitoring Methods for Radiation Protection. NCRP Report No. 57, NCRP Publications, Washington, D.C.

Plato, P., and G. Hudson. 1980. Performance Testing of Personnel Dosimetry Services: Final Report of a Two-Year Pilot Study. NUREG/CR-1064, U.S. Nuclear Regulatory Commission, Washington, D.C. 
Roberson, P. L., K. L. Holbrook, R. C. Yoder, R. A. Fox, R. T. Hadley, B. T. Hogan, and C. D. Hooker. 1983. Performance Comparisons of Selected Personnel Dosimetry Systems in Use at Department of Energy Facilities. PNL-3893, Pacific Northwest Laboratory, Richland, Washington.

Roberson, P. L., and K. L. Holbrook. 1984. Guidelines for the Calibration of Personal Dosimeters. PNL-4515. Pacific Northwest Laboratory, Richland, Washington.

Roberson, P. L., F. N. Eichner, and W. D. Reece. 1986. Determination of Photon Conversion Factors Relating Exposure and Dose for Several Extremity Phantom Designs. PNL-5660, Pacific Northwest Laboratory, Richland, Washington.

Schwartz, R. B., and C. M. Eisenhauer. 1980. The Design and Construction of a D20-Moderated $252 \mathrm{Cf}$ Source for Calibrating Neutron Personnel Dosimeters Used at Nuclear Power Reactors. NUREG/CR-1204, U.S. Nuclear Regulatory Commission, Washington, D.C.

Schwartz, R. B., and C. M. Eisenhauer. 1982. Procedures for Calibrating Neutron Personnel Dosimeters. NBS Special Publication 633, U.S. Department of Commerce, National Bureau of Standards, Washington, D.C.

U.S. Department of Energy (DOE). 1986. Department of Energy Standard for the Performance Testing of Personnel Dosimetry Systems. DOE Laboratory Accreditation Program for Personnel Dosimetry Systems. DOE/EH-0027, Washington, D.C.

U.S. Department of Energy (DOE). 1988. DOE Order 5480.11, "Radiation Protection for Occupational Workers."

U.S. National Bureau of Standards (NBS). 1986. NBS Calibration Services Users Guide. NBS Special Publication 250, U.S. Government Printing Office, Washington, D.C. 
APPENDIX A

ASSESSMENT OF UNCERTAINTIES 


\section{APPENDIX A}

\section{ASSESSMENT OF UNCERTAINTIES}

The dose equivalent, $H$, or dose, $D$, delivered to the sensitive element of a dosimeter can be expressed as follows:

Photon (sealed source)

$$
H=\dot{x}\left(d_{c}\right) \cdot c_{x} \cdot\left(\frac{d_{c}}{d_{p}}\right)^{2} \cdot\left(\frac{d_{p}}{d_{p}-d_{e}}\right)^{2} \cdot f_{Q} \cdot t+D_{B}
$$

Photon (x-ray)

$$
H=T\left(d_{c}\right) \cdot C_{x} \cdot M \cdot\left(\frac{d_{c}}{d_{p}}\right)^{2}\left(\frac{d_{p}}{d_{p}-d_{e}}\right)^{2} \cdot f_{Q} \cdot C_{T P}+D_{B}
$$

Beta

$$
D=\dot{D}\left(d_{c}\right) \cdot\left(\frac{d_{c}}{d_{p}}\right)^{2} \cdot\left(\frac{d_{p}}{d_{p}-d_{e}}\right)^{2} \cdot f_{Q} \cdot t \cdot c_{t}+D_{B}
$$

Neutron

$$
H=\left(\frac{3600}{4 \pi}\right) \cdot N \cdot C_{N} \cdot t \cdot f_{Q}\left(\frac{1}{r^{2}+r_{p}^{2}}\right)\left(\frac{r}{d_{p}}\right)^{2}+D_{B}
$$

where $\dot{x}\left(d_{c}\right)$ is the exposure rate at the calibration distance, $d_{c}$, without the phantom. This quantity is measured with NIST calibrated transfer chambers and verified with the NIST measurement quality assurance program. The uncertainty is systematic.

$C_{x}$ is the conversion factor from Roentgen to rem in the presence of a phantom. In this equation, $C_{x}$ incorporates the quality factor, $Q$, that converts rad to rem. The uncertainty for $C_{x}$ is not included in the total uncertainty. This factor is used by the testing laboratory and the participants, so that no irradiation uncertainty is associated with its use. 
$d_{c}$ is the distance from the source to the calibration point. Its uncertainty is included in the uncertainty in $X\left(d_{c}\right), T\left(d_{c}\right)$, or $D\left(d_{c}\right)$.

$d_{p}$ is the distance from the source to the phantom surface. It is intended to be equal to $d_{c}$ (or $r$ ). It is explicitly included so that random errors in determining $d_{p}$ can be included in the uncertainty analysis.

$d_{e}$ is the distance from the phantom surface to the midpoint of the sensitive element(s) when the dosimeter is mounted on the phantom for irradiation. Dosimeters are mounted parallel to the phantom surface. de can have both random and systematic uncertainties.

$f_{Q}$ is the ratio of the dose rate at the position of the dosimeter to the dose rate at the center of the phantom. It has a systematic uncertainty.

$t$ is the exposure time. The systematic uncertainty is minimized by timing measurements and, if necessary, appropriate correction factors. Random uncertainty is present.

$D_{B}$ is the difference between the background dose or dose equivalent received by the test dosimeters and that received by the control dosimeters. This may occur during the time the test dosimeters are separated from the control dosimeters during an exposure period, normally less than 8 hours. The uncertainty is random.

$T\left(d_{c}\right)$ is the calibration value for the $x$-ray technique in units of exposure per charge recorded by the transmission chamber. This quantity is measured with a NIST-calibrated chamber and verified with the NIST measurement quality assurance program. The calibration factors are checked and adjusted quarterly unless problems are indicated by the internal quality control program. The uncertainty is systematic.

$M$ is the reading of the transmission chamber. The uncertainty is random.

CTP is the temperature and pressure correction factor required for the transmission chamber reading. The room conditions are monitored continuously. Most of the uncertainty is random. There may be some systematic uncertainty if the monitoring temperature device is not inside the transmission chamber.

$\dot{D}\left(d_{c}\right)$ is the dose rate measured with an in-house extrapolation chamber or measured by NIST. The in-house extrapolation chamber is calibrated using a source calibrated by NIST or traceabie to NIST. The uncertainty is systematic because the calibration is determined before the test irradiations and changed infrequently (e.g., quarterly). 
$C_{t}$ is the transmission factor necessary if the NIST calibration was performed at a different tissue depth than the source calibration. The uncertainty is systematic. This factor is typically unity with no uncertainty.

$N$ is the neutron emission rate, calibrated by NIST. The uncertainty is due to the NIST calibration and source decay. Source decay uncertainty is small. The total uncertainty is systematic.

$C_{N}$ is the flux-to-dose-equivalent conversion factor recommended by NIST. This factor is used by the testing laboratory and the participants, so that no irradiation uncertainty is associated with its use.

$r$ is the theoretical distance to the calibration point. The ratio $r / d_{p}$ represents the assumed unity value associated with the measurement of the source-to-phantom distance.

$r_{p}$ is the distance from the center of the phantom to the dosimeter position. Random uncertainties result from the placement of the dosimeter. Systematic uncertainties occur because of the placement of the position of the sensitive element in the dosimeter. 
APPENDIX B

COMPILATION OF DOSIMETER PERFORMANCE DATA 


\section{APPENDIX B}

\section{COMPILATION OF DOSIMETER PERFORMANCE DATA}

This appendix contains the performance data for the dosimeters tested in this study. The results for the ring dosimeters are presented in Tables B.1 through B.8. The results for the wrist dosimeters are presented in Tables B.9 through B.13. The tables are organized by category. Each table contains the processor identification codes $(A-1)$ for each of the dosimeters submitted for that specific category. The tables list the bias and standard deviation for each of the three rounds of testing (labeled "Initial Results"). In addition, the tables for Categories IIIA through VII include the data submitted following disclosure of the dosimeters irradiated in each category (labeled "Categories Identified"). 
TABLE B.1. Category I - Ring Dosimeters

\begin{tabular}{|c|c|c|c|c|c|}
\hline \multirow[b]{2}{*}{$\begin{array}{c}\text { Processor } \\
\text { Code }\end{array}$} & \multirow[b]{2}{*}{ Round } & \multirow[b]{2}{*}{ Source } & \multicolumn{3}{|c|}{ Initial Results } \\
\hline & & & Bias (B) & $\begin{array}{c}\text { Standard } \\
\text { Deviation } \\
\text { (S) }\end{array}$ & $|B|+S$ \\
\hline A & $\begin{array}{l}1 \\
2 \\
3\end{array}$ & $\begin{array}{l}\text { M150 } \\
\text { M150 } \\
\text { M150 }\end{array}$ & $\begin{array}{c}-0.027 \\
0.203 \\
\text { NRYa }\end{array}$ & $\begin{array}{l}0.325 \\
0.042 \\
N R\end{array}$ & $\begin{array}{l}0.352 \\
0.249 \\
N R\end{array}$ \\
\hline B & $\begin{array}{l}1 \\
2 \\
3\end{array}$ & $\begin{array}{l}\text { M150 } \\
\text { M150 } \\
\text { M150 }\end{array}$ & $\begin{array}{r}0.479 \\
0.297 \\
-0.229\end{array}$ & $\begin{array}{l}0.444 \\
0.198 \\
0.088\end{array}$ & $\begin{array}{l}0.924 \\
0.495 \\
0.317\end{array}$ \\
\hline D & $\begin{array}{l}1 \\
2 \\
3\end{array}$ & $\begin{array}{l}\text { M150 } \\
\text { M150 } \\
\text { M150 }\end{array}$ & $\begin{array}{l}0.159 \\
0.437 \\
\text { NR }\end{array}$ & $\begin{array}{l}0.092 \\
0.060 \\
N R\end{array}$ & $\begin{array}{l}0.251 \\
0.497 \\
N R\end{array}$ \\
\hline$H$ & $\begin{array}{l}1 \\
2 \\
3\end{array}$ & $\begin{array}{l}\text { M150 } \\
\text { M150 } \\
\text { M150 }\end{array}$ & $\begin{array}{r}0.437 \\
-0.219 \\
0.318\end{array}$ & $\begin{array}{l}0.154 \\
0.036 \\
0.106\end{array}$ & $\begin{array}{l}0.591 \\
0.255 \\
0.424\end{array}$ \\
\hline
\end{tabular}

(a) $\quad$ NR $=$ No Results 
TABLE B.2. Category II - Ring Dosimeters

\begin{tabular}{|c|c|c|c|c|c|}
\hline \multirow[b]{2}{*}{$\begin{array}{c}\text { Processor } \\
\text { Code } \\
\end{array}$} & \multirow[b]{2}{*}{ Round } & \multirow[b]{2}{*}{ Source } & \multicolumn{3}{|c|}{ Initial Results } \\
\hline & & & Bias (B) & $\begin{array}{c}\text { Standard } \\
\text { Deviation } \\
\text { (S) } \\
\end{array}$ & $|B|+S$ \\
\hline A & $\begin{array}{l}1 \\
2 \\
3\end{array}$ & $\begin{array}{l}137 \mathrm{Cs} \\
137 \mathrm{Cs} \\
137 \mathrm{Cs}\end{array}$ & $\begin{array}{r}-0.296 \\
-0.933 \\
N R(a)\end{array}$ & $\begin{array}{l}0.320 \\
0.061 \\
N R\end{array}$ & $\begin{array}{l}0.616 \\
0.098 \\
N R\end{array}$ \\
\hline B & $\begin{array}{l}1 \\
2 \\
3\end{array}$ & $\begin{array}{l}137 \mathrm{Cs} \\
137 \mathrm{Cs} \\
137 \mathrm{Cs}\end{array}$ & $\begin{array}{l}0.613 \\
0.640 \\
0.046\end{array}$ & $\begin{array}{l}0.104 \\
0.071 \\
0.097\end{array}$ & $\begin{array}{l}0.717 \\
0.712 \\
0.143\end{array}$ \\
\hline D & $\begin{array}{l}1 \\
2 \\
3\end{array}$ & $\begin{array}{l}13 \% \mathrm{Cs} \\
137 \mathrm{Cs} \\
137 \mathrm{Cs}\end{array}$ & $\begin{array}{l}0.006 \\
0.324 \\
N R\end{array}$ & $\begin{array}{l}0.037 \\
0.065 \\
\text { NR }\end{array}$ & $\begin{array}{l}0.043 \\
0.388 \\
\text { NR }\end{array}$ \\
\hline$F$ & $\begin{array}{l}1 \\
2 \\
3\end{array}$ & $\begin{array}{l}137 \mathrm{Cs} \\
137 \mathrm{Cs} \\
137 \mathrm{Cs}\end{array}$ & $\begin{array}{r}0.093 \\
-2.113 \\
-0.001\end{array}$ & $\begin{array}{r}0.065 \\
-0.041 \\
0.032\end{array}$ & $\begin{array}{l}0.158 \\
0.154 \\
0.033\end{array}$ \\
\hline$H$ & $\begin{array}{l}1 \\
2 \\
3\end{array}$ & $\begin{array}{l}137 \mathrm{Cs} \\
137 \mathrm{Cs} \\
137 \mathrm{Cs}\end{array}$ & $\begin{array}{r}0.122 \\
-0.094 \\
-0.079\end{array}$ & $\begin{array}{l}0.221 \\
0.198 \\
0.060\end{array}$ & $\begin{array}{l}0.343 \\
0.293 \\
0.138\end{array}$ \\
\hline
\end{tabular}

(a) $N R=$ No Results. 


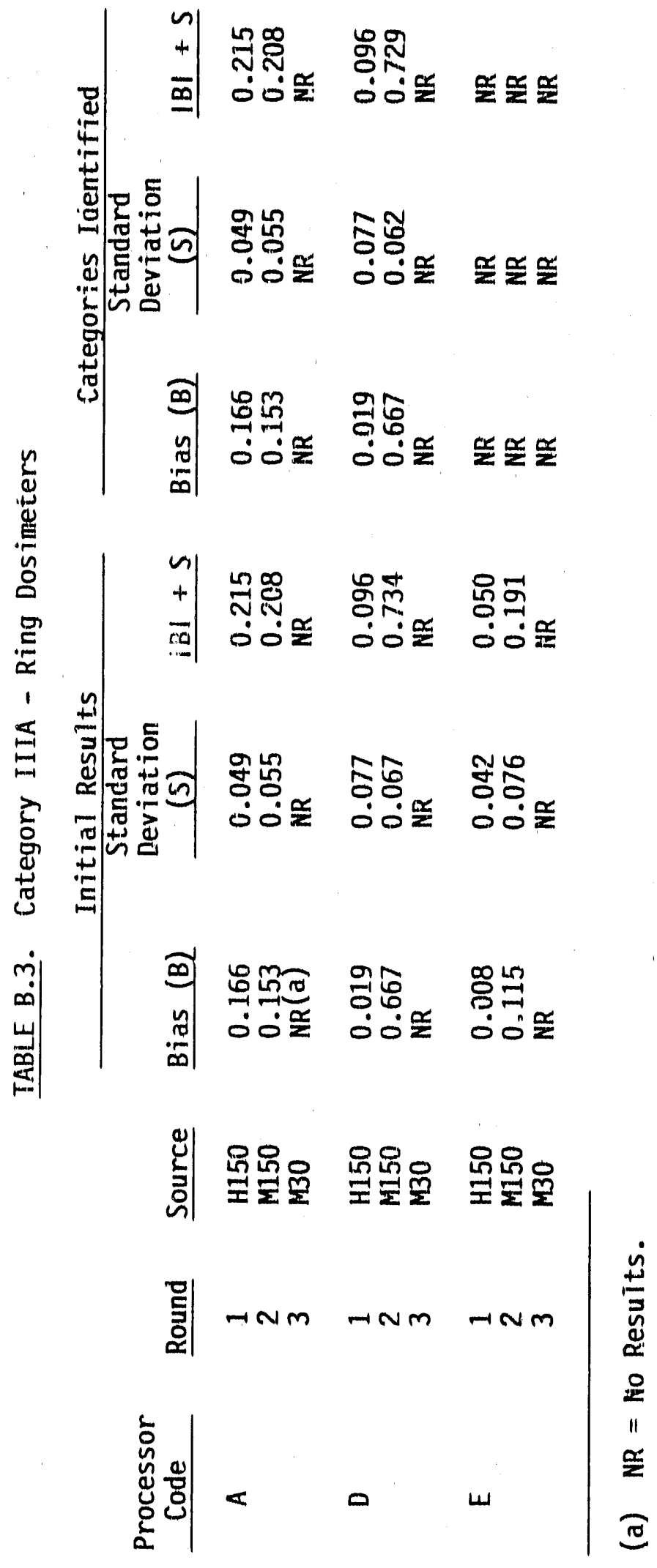

B. 4 


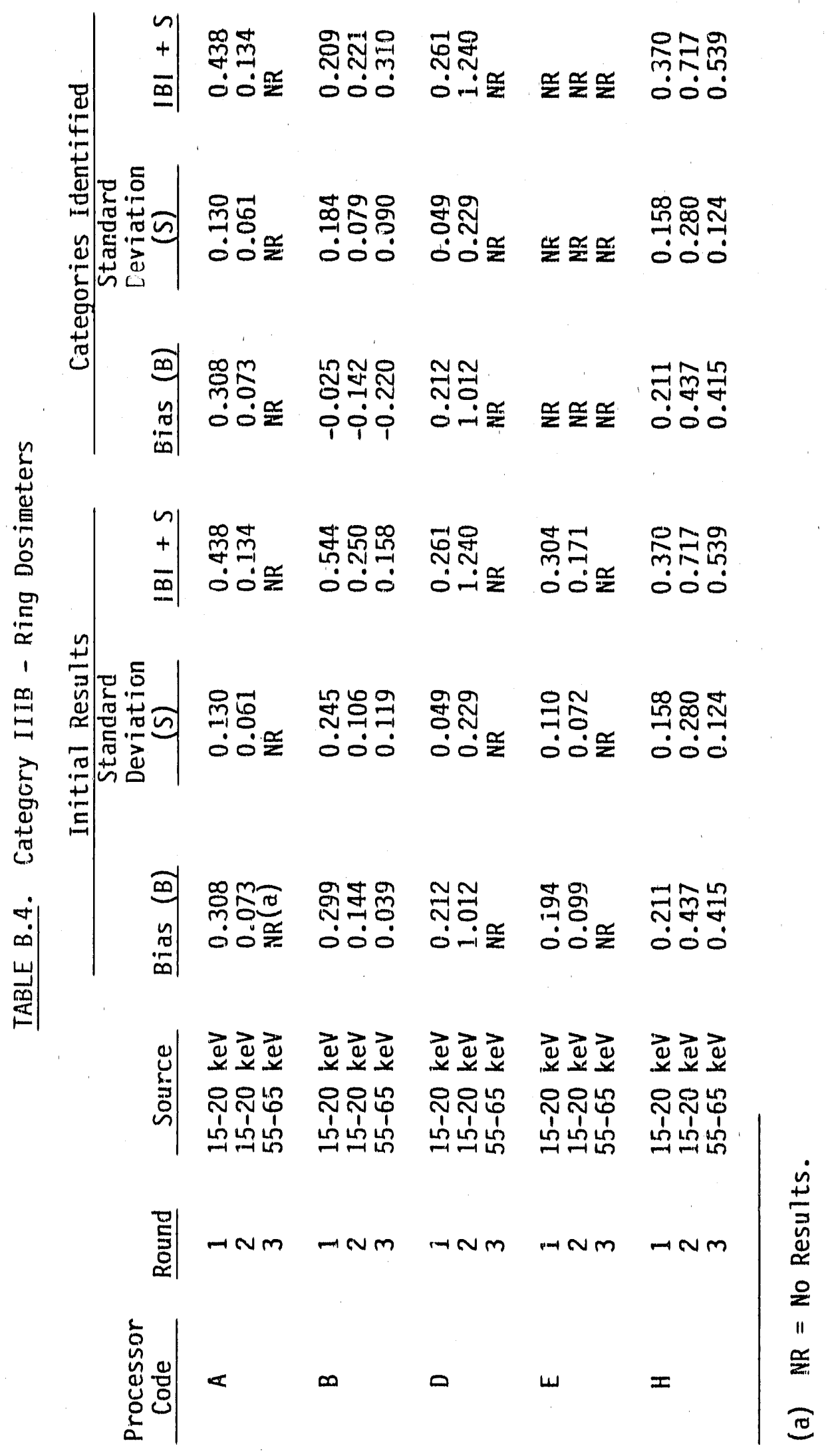




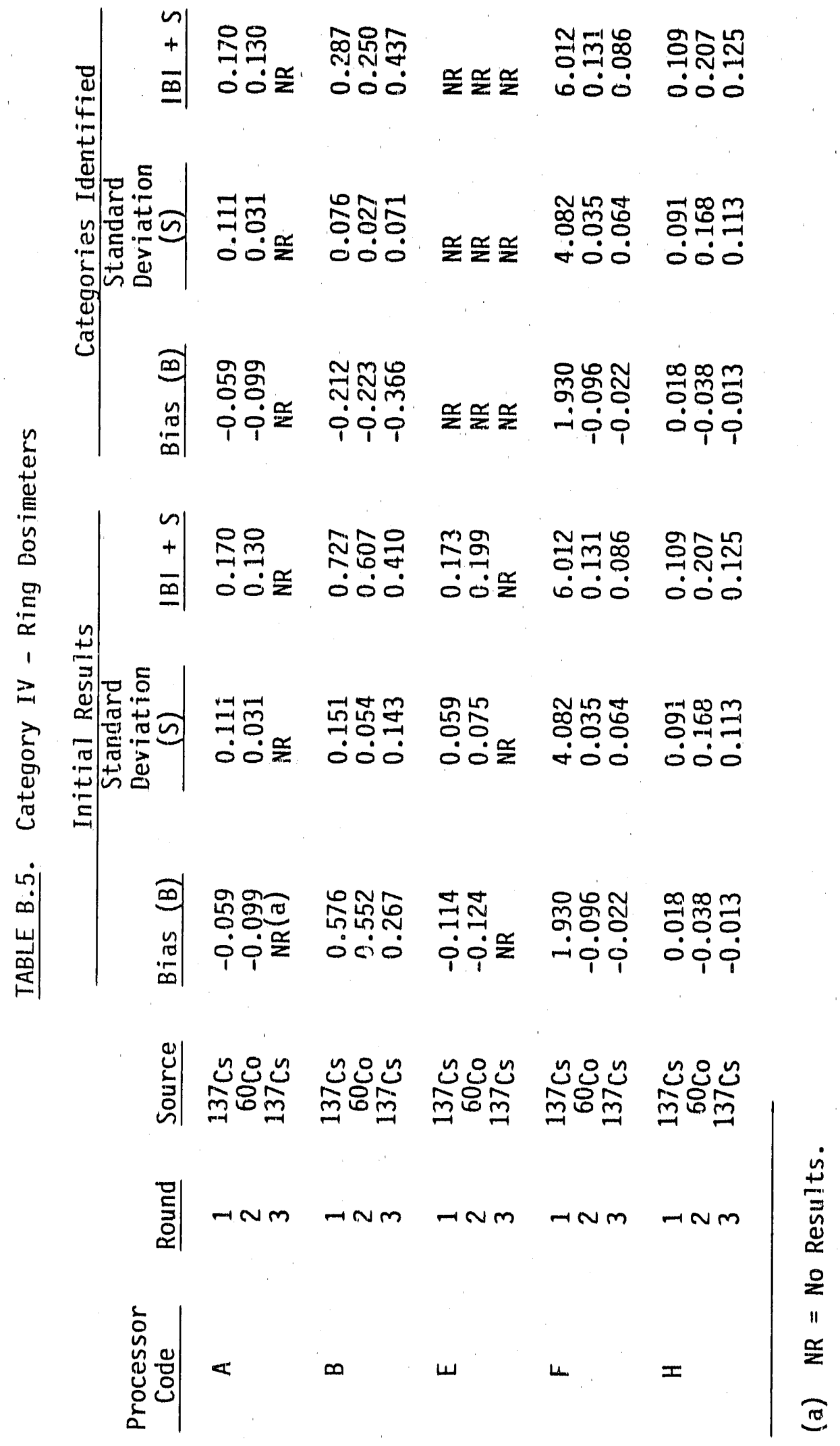

B. 6 


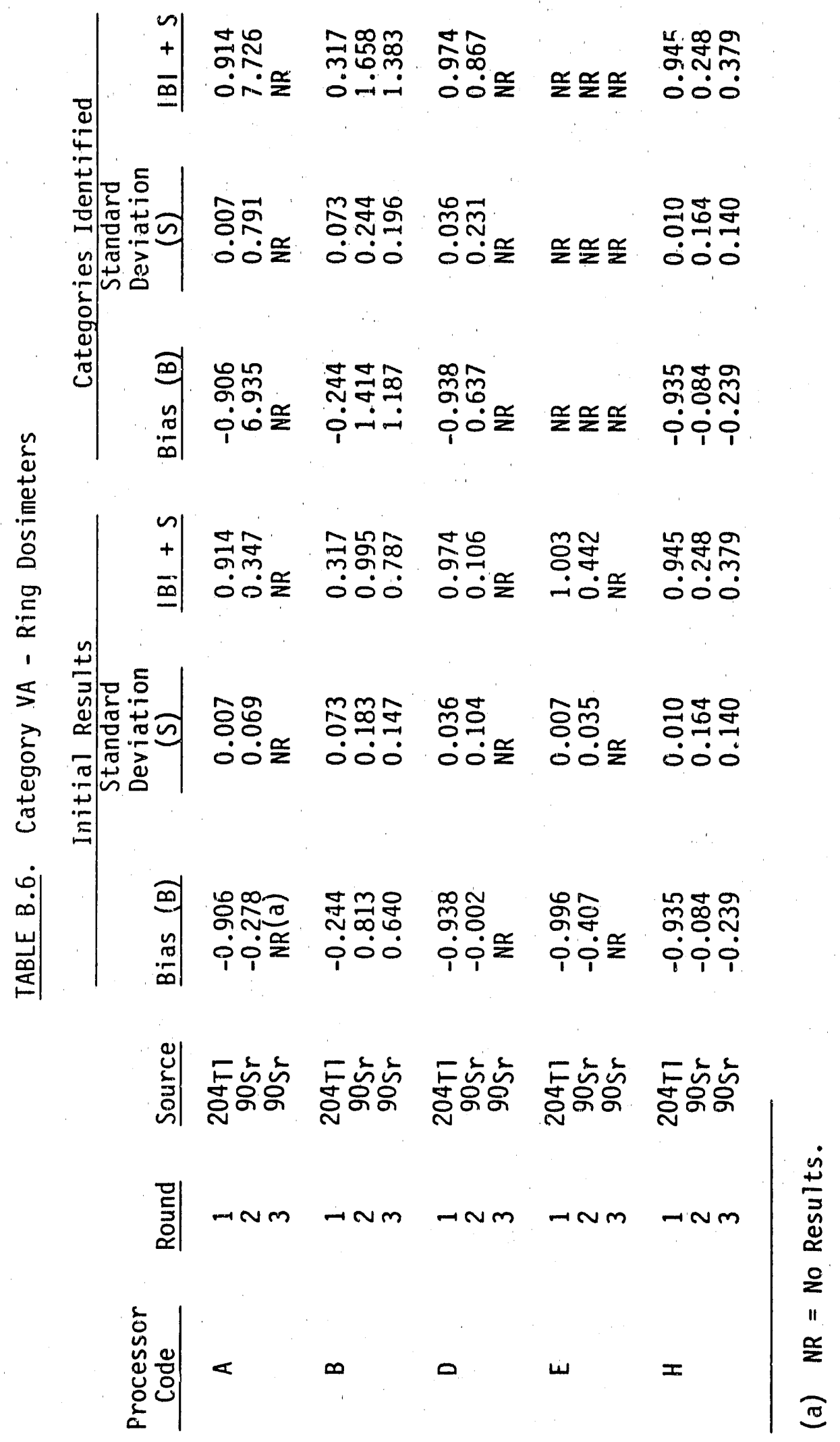



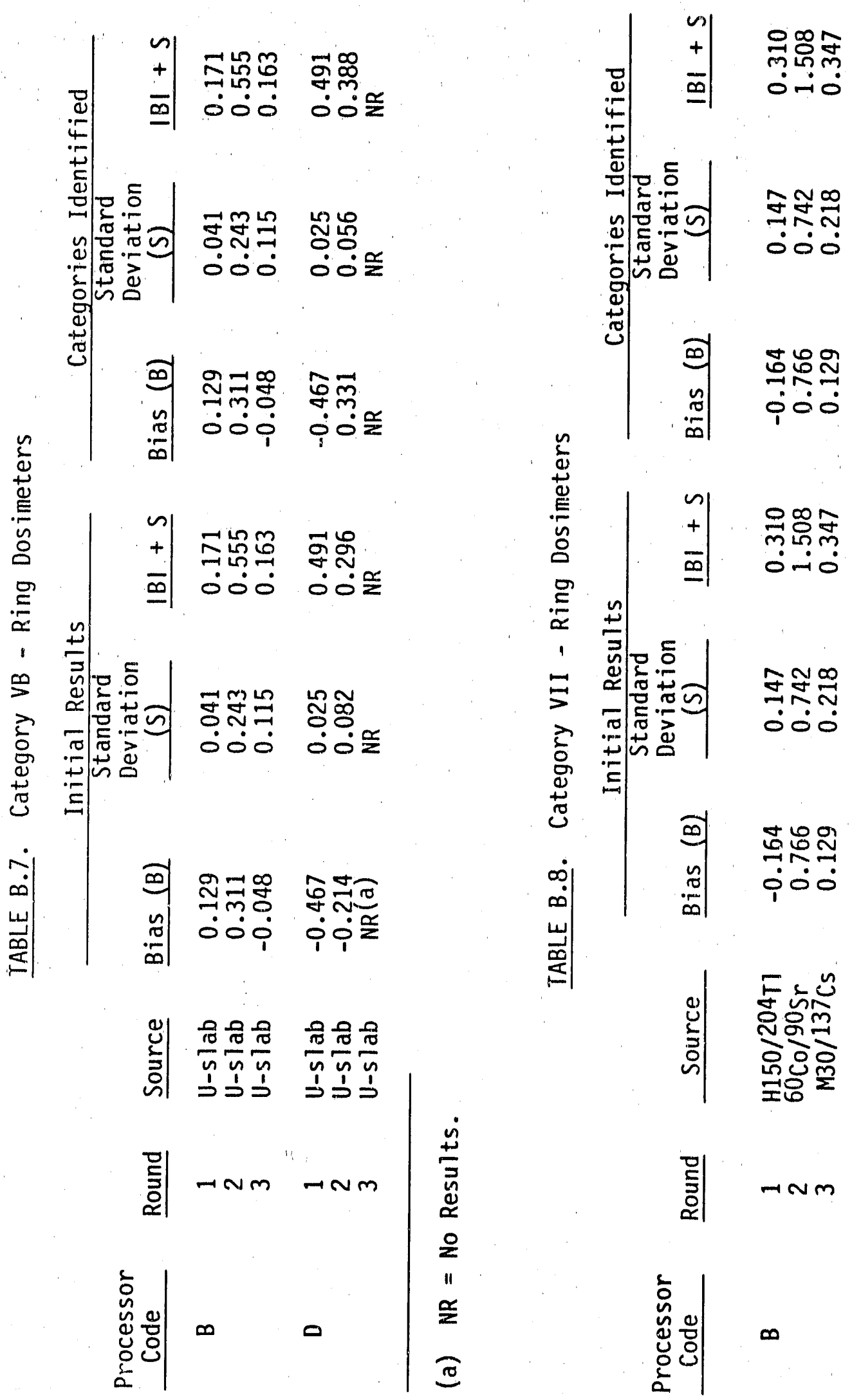

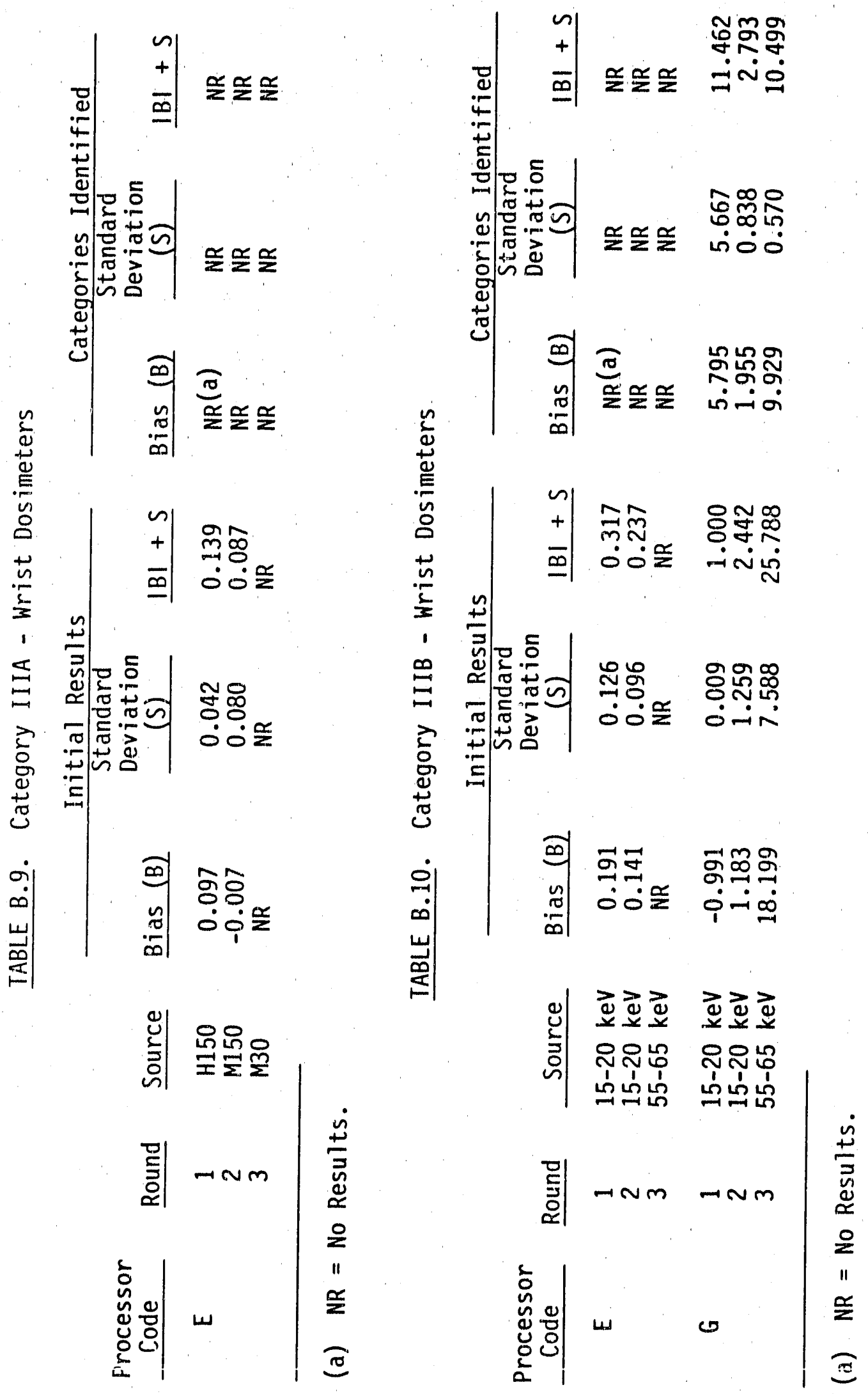

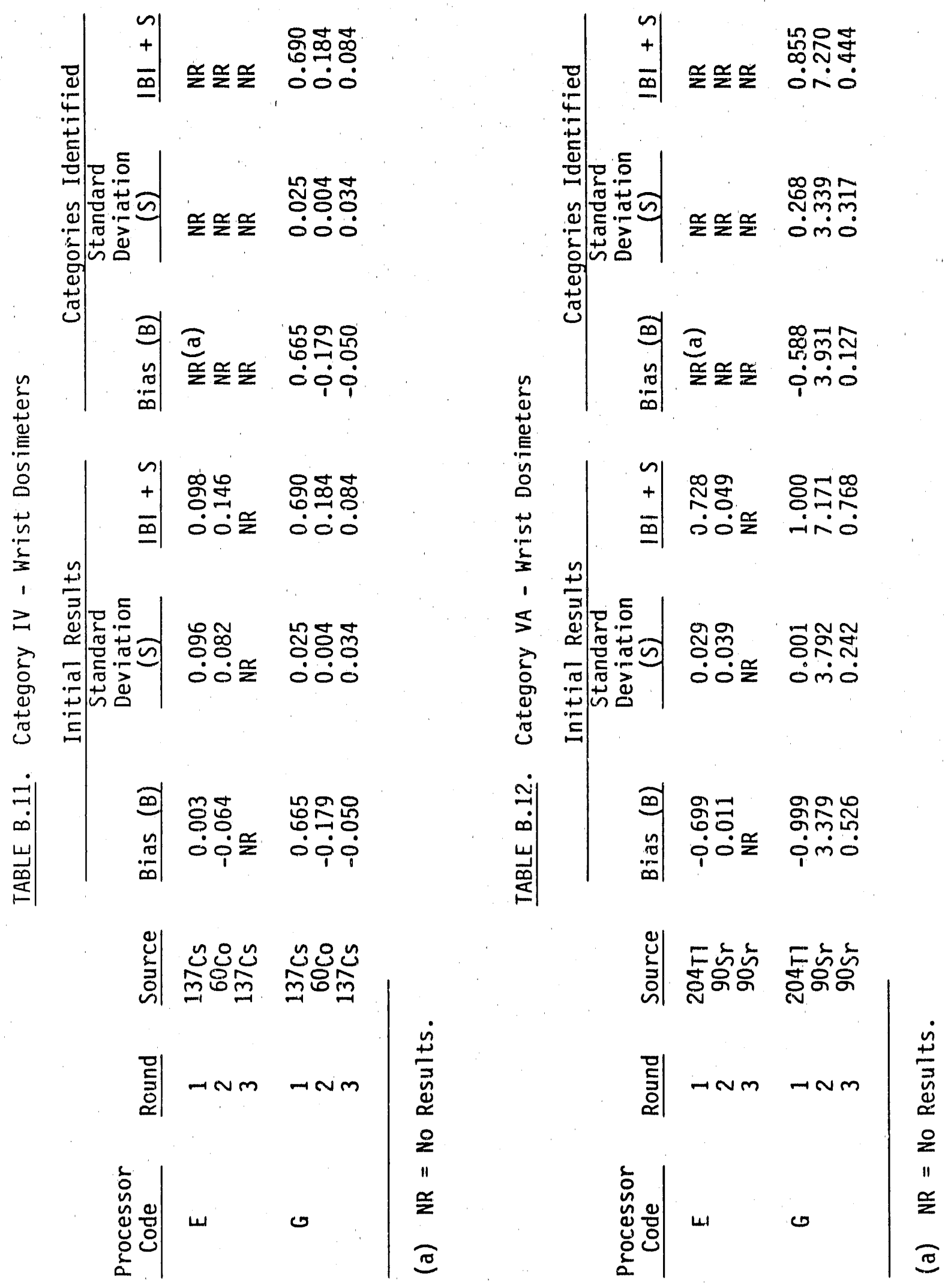


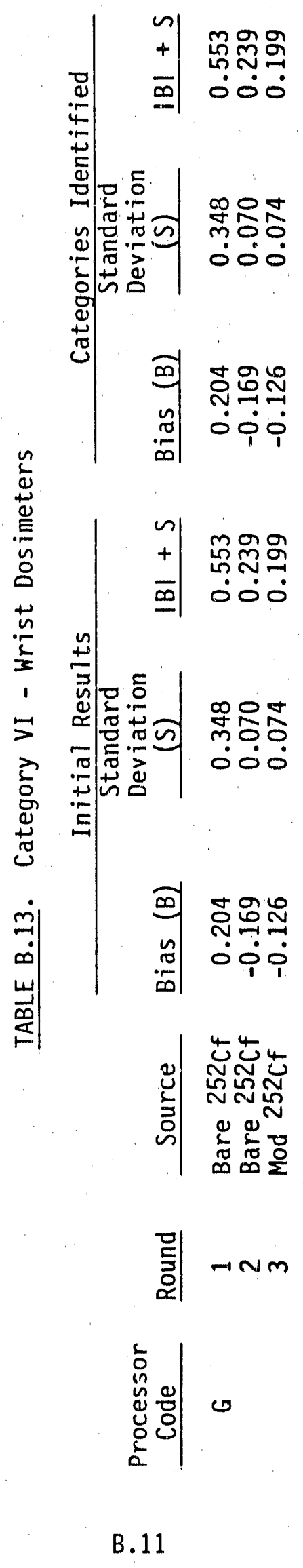



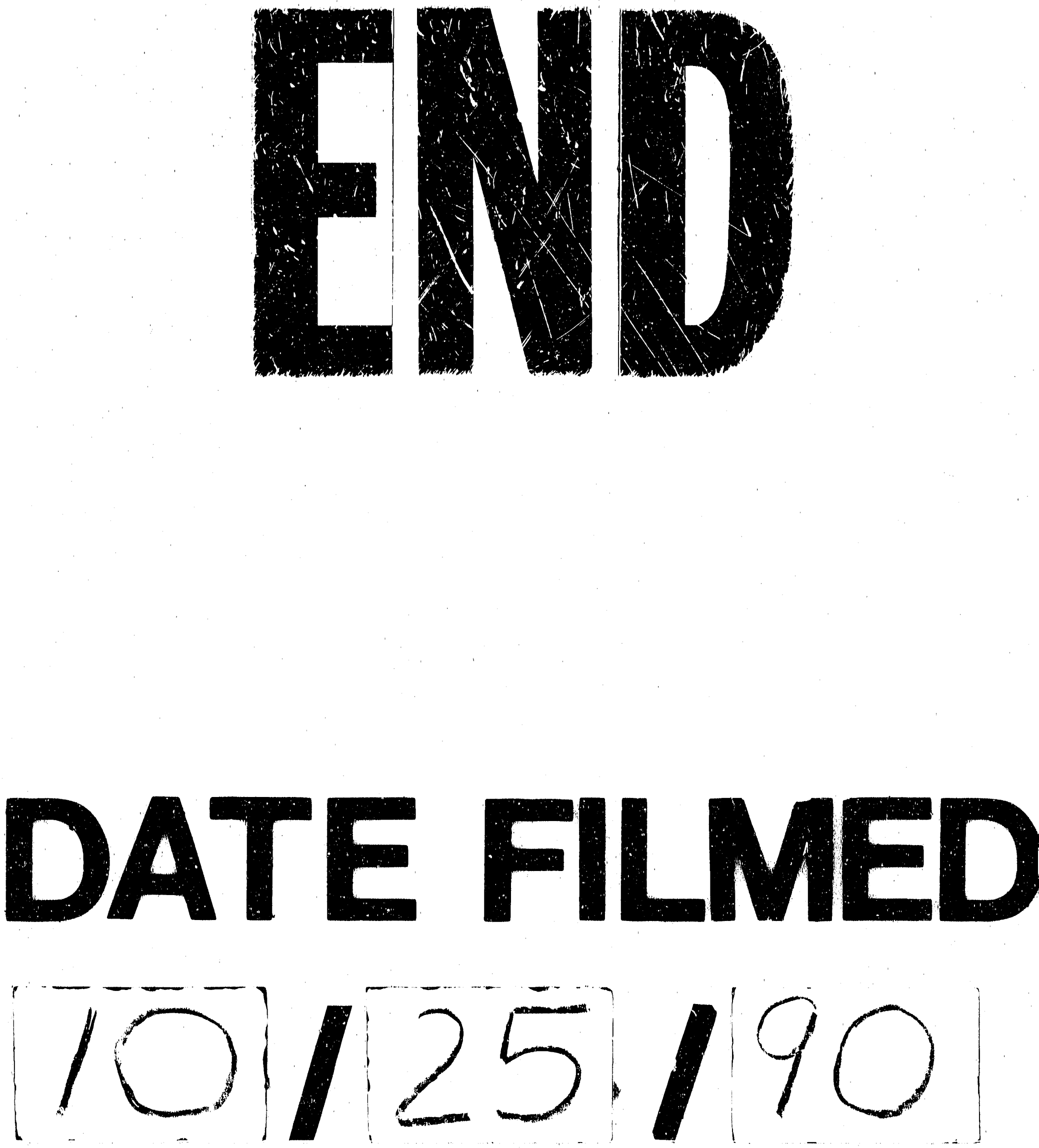
